\title{
URBANISMO FLUVIAL EN EL APOGEO INDUSTRIAL DE VALDIVIA: DESAPARICIÓN Y RECUPERACIÓN (ca. 1850-2012).1
}

Fluvial urbanism during Valdivia's industrial heyday: disappearance and recovery (1850 - 2012)

Gerardo Saelzer C.*, Simón Urbina A.**

\section{Filiación}

* Instituto de Arquitectura y Urbanismo, Universidad Austral de Chile

** Dirección Museológica, Universidad Austral de Chile

E mail: gsaelzer@gmail.com, simon.urbina@uach.cl

Primera versión recibida en: 11 de noviembre, 2014

Última versión recibida en: 25 de diciembre, 2015

\section{Resumen}

El presente estudio analiza procesos productivos y arquitectónicos que transformaron el eje fluvial de Valdivia en recurso urbano, operaciones que al desaparecer han dejado en evidencia conflictos de desarrollo territorial. Las valoraciones históricas en el modelo de la ciudad en curso afectan sitios conectados con el espacio fluvial, recursos arqueológicos y patrimoniales. Se plantea que las conquistas logradas en las riberas durante el apogeo industrial se terminan por desarmar si no se resuelve el río como componente de la ciudad, específicamente del paisaje urbano. El presente estudio sistematiza los primeros indicadores inmuebles y cartográficos derivados de las etapas iniciales y avanzadas de la industria. Desde una perspectiva diacrónica y territorial, se localizan estos indicadores, tipologías arquitectónicas y valores del paisaje, orientados a un rescate cultural del espacio fluvial que incluya fomentar proyectos culturales basados en nuevas investigaciones interdisciplinarias, permitiendo discutir con bases empíricas el paradigma de planificación sectorial vigente.

\section{Palabras clave}

Período Industrial; urbanismo fluvial; ciudad de Valdivia.

\begin{abstract}
The inadequate appreciation of Valdivia's urban evolution has influence on current planning decisions affecting more and more archaeological and architectural remains inside city area. In according to that situation, aesthetics values, architectural indicators and typologies derived from both early and advanced stage of industrial process at Valdivia are localized from a diachronic and territorial perspective. It was also conclude that conservation or recovery projects must be based on interdisciplinary scientific researches, in order to discuss present urban planning models.
\end{abstract}

\section{Key words}

Industrial Period; fluvial urbanism; city of Valdivia.

\section{Sumario}

Introducción

1 El período preindustrial: integración geopolítica y refuerzo poblacional.

2 Apogeo industrial, comunicación fluvial y urbanismo temprano.

3 Escalas urbanizadoras y experimentación arquitectónica

\footnotetext{
${ }^{1}$ Este trabajo es resultado del Proyecto FONDECYT 1130730 Arqueología histórica de la ciudad de Valdivia y su jurisdicción en el período colonial. Universidad Austral de Chile.
} 
3.1 Escalas arquitectónicas de transformación urbana.

3.2 Tipologías y procedimientos materiales.

4 Extensión de la ciudad

4.1 Ribera, primeras propiedades y operaciones territoriales.

4.2 Dimensión productiva, social e inter comunicación

5 Operaciones constructivas, formas y complejidad del espacio paisajístico.

6 Discusión y conclusiones

6.1 Estéticas, éticas y políticas: la desaparición de las formas arquitectónicas.

Bibliografía

\section{Introducción}

Interfaces centroeuropea-sudamericanas ${ }^{2}$ que desde temprano produjeron nuevas formas arquitectónicas en localidades de arribo, reemplazaron tipologías preexistentes (Pellegrini y Aprille, 1924). En Valdivia ocasionaron un cambio urbano, comenzando por el Área Fundacional colonial

El período 1820-2012 permite revisar, identificar, describir y generar las bases de los períodos en los que se consignan procesos urbanos entorno al río. El caso -urbanismo fluvial, desaparición y recuperación-, se sitúa entre 1850 y 2012. Se emplea el neologismo de Cerda en su acepción amplia. La calificación "fluvial" se establece en función del análisis de la cartografía histórica de Valdivia respecto a las posiciones del río y el protagonismo que, en las fotografías de la ciudad, adquieren los bordes como fachadas enfrentadas a través de ese cauce.

El estado de desarrollo industrial expresado en las infraestructuras y colonización del río, tuvo como contexto las acciones extractivas y de producción perfiladas a lo largo del s. XVIII (Guarda, 1973:75). Las instalaciones para manufactura dispuestas sobre una organización predial desde entonces heredada, junto a la extensión de predios adquiridos por los inmigrantes en el s. XIX, devinieron articulaciones productivas y transformación de escenarios, generando que el casco o Área Fundacional se integrara con el río.

Los ensayos urbanísticos que se intentaron sobre el Área Fundacional desde la segunda mitad del siglo XIX, en la nueva extensión derivaron en expresiones de urbanismo espontáneo, debido a que se trata de iniciativas independientes, adecuaciones fisiográficas, sin mediar dibujos guías, pero un espacio común que confiere un sentido de actividad colectiva.

En el plano teórico se analiza el desarrollo de la ciudad en función del ordenamiento territorial (Gómez, 2008), la recuperación contemporánea de la idea del paisaje -paisaje urbano (Maderuelo, 2010)- , además variables turismo-lógicas (Yazigi, 2002, 2009) como elementos de transformación que, en ciertos aspectos, aluden al problema del esclarecimiento del recuerdo para la construcción de identidad (Assmann, 1999: 85 y 92).

La progresiva y sistemática demolición de aquellas infraestructuras que dieron pauta y recursos urbanísticos, dejan actualmente al descubierto un conflicto que se manifiesta como la ausencia de herencias materiales y espaciales, lo que resulta en la pérdida de patrimonio (Fig. 1a-b) y la consecuente relación del pasado con el futuro. Como elementos que podrían emplearse como

2 Inmigraciones de segunda mitad del s.XIX e inicios del s.XX, estudiadas por diferentes autores, que aportan reflexiones sobre nuevas territorialidades en el sur de Brasil, Buenos Aires provincia e interior de Argentina, sur y costa central de Chile. 
insumos para replantear el espacio fluvial, se cuenta con la identificación de al menos la silueta colonial, la de una etapa y estado finicolonial e industrial de la ciudad-puerto, y la transformación del recuerdo en un fenómeno inmaterial. Es decir, la recolonización silvestre, la edificación tanto inmobiliaria como vial de los bordes, y las interpretaciones históricas como parte del desarrollo del paisaje urbano en la esfera cultural (Corner, 2005).
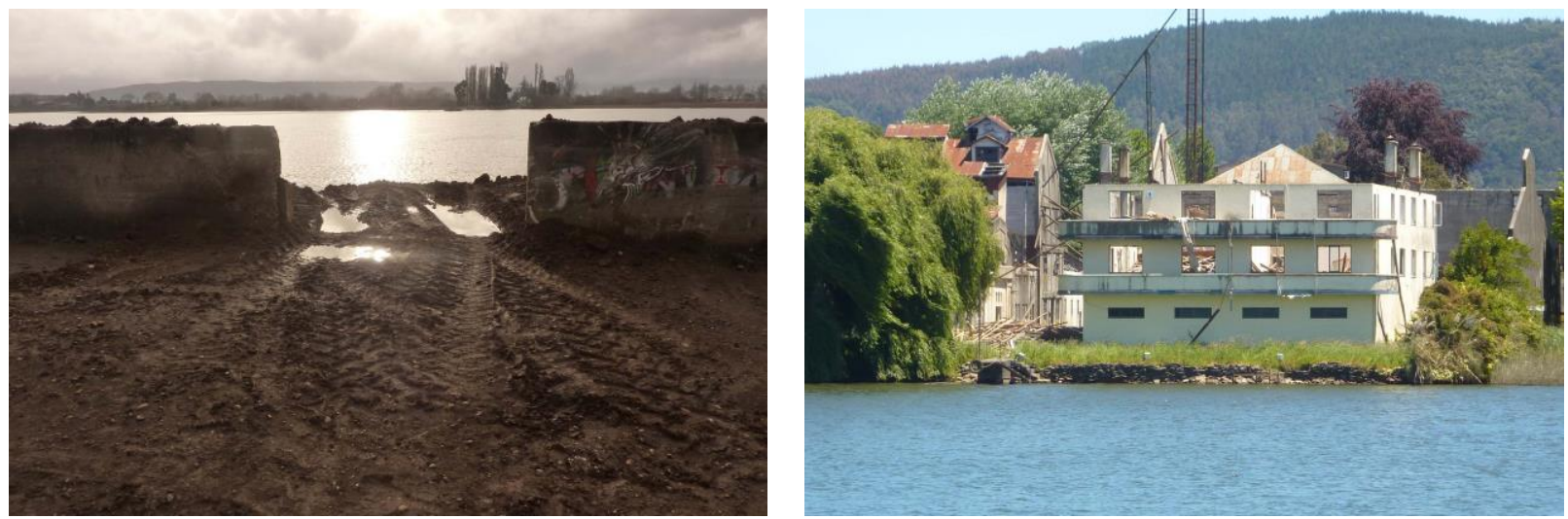

Fig. 1

a. (Izquierda) Bodegas carga-descarga fluvial y ferrocarriles, demolidas, Collico, ca. 2012.

b. (Derecha) SAIC Hoffmann, en demolición, Isla Teja, ca. 2012.

Fuente: Colección Gerardo Saelzer.

Los primeros registros sistemáticos de las formas arquitectónicas estudiadas desde la arqueología - p.e. muros de ladrillo y fundaciones de piedra laja bajo el entonces Hotel Pedro de Valdivia (hoy Casino de Valdivia) o Mirador Yungay (hoy Contraloría Regional)- han comprendido el relevamiento y análisis de testimonios arquitectónicos in situ. Dichos estudios contemplan adicionalmente el mapeo de materiales constructivos fragmentados -como tejas curvas, tejas planas con gancho y ladrillos- provenientes de diversos yacimientos coloniales y republicanos que afloran permanentemente de modo superficial en el sector que se ha denominado presentes en el Área Fundacional de Valdivia (Urbina et al., 2012). Metodológicamente, la investigación de testimonios arquitectónicos in situ de data colonial o republicana ha impulsado el estudio de fuentes documentales, fotográficas y cartográficas, sin las cuales sería imposible reconstituir las características y tipologías arquitectónicas presentes en Valdivia a los largo del siglo XIX e inicios del siglo XX. El caso emblemático en este sentido son las excavaciones extensivas practicadas para exponer las fundaciones de edificios propios del Período del Apogeo Industrial, como la Aduana de Valdivia (Mera et al. 2014), permitiendo asimilar resultados de la convergencia entre historia, arquitectura y arqueología, en una correcta valoración y puesta en valor de los recursos patrimoniales que impulsa actualmente no sólo nuevas investigaciones, sino la conservación de las fundaciones de este edificios para estudios futuros y la inauguración de una sala interpretativa donde se exhiben restos de arquitectura en ladrillo y elementos de la cultura material asociada al período Alfarero Tardío (ca. 1100-1552), de Colonial (ca. 1552-1820) y Republicano (ca. 1850).

En términos metodológicos, el artículo se propone enfocar el caso de prácticas urbanas en el espacio fluvial de Valdivia, desde un marco general con bajadas hacia marcos particulares. El material histórico y el contexto territorial, expuestos desde la cartografía histórica hasta una planimetría contemporánea, constituyen el marco general. Fueron revisados archivos fotográficos y documentales -cartografías y planimetrías-, priorizando aquellas piezas inéditas. El análisis de las varias capas de información sobre la ocupación urbana ocurridas en el espacio de la cuenca hidrográfica, configuran relaciones complejas, comenzando a requerirse un trabajo 
interdisciplinario que integre la historia, la arquitectura y la arqueología. Como caso particular se expone un material inédito que permite incursionar en el análisis, como ejemplo metodológico y también como recurso de valor: fuentes visuales sobre Valdivia y el complejo industrial Hoffman, ca. 1870 hasta su total desmantelamiento en 2012.

\section{El período preindustrial: integración geopolítica y refuerzo poblacional.}

La trascendencia de Valdivia comienza quizás a delinearse en 1741, al dejar de depender administrativamente del Virreinato del Perú e incorporarse al Reino de Chile. Aun mediando la destrucción por el incendio de 1748, el río permaneció como el conducto de la estructura institucional radicada la isla de Mancera. El registro de comercio de 1782 a 1820 (Guarda, 1973: 58-74) refuerza la identidad de esta cuenca como enclave manufacturero, reconocida además como puerto oficial para el libre comercio en 1811 (Guarda, 1973: 66). Para la ciudad, ya provincia en 1826, las condiciones de lo que no era tierra firme definieron un sentido de organización que hoy denominamos geopolíticos, pero la proyección urbana fue escaza. El orden social y la gobernabilidad de Valdivia se hicieron vulnerables tras la incorporación de la ciudad a la república (ca.1820), transcurriendo tres decenios de debilidades políticas, institucionales, demográficas, económicas y urbanísticas (Bernedo, 1999: 39-40; Guarda, 2001: 480)33. En esta primera mitad del siglo XIX la ciudad mantiene coordinación con el océano Pacífico, pero no necesariamente con el río. Se ocupó una única ribera, además parcialmente, mediante un punto de conexión: un muelle.

La apuesta del Estado por un desarrollo rural mediante la recepción de inmigrantes, a través de la Ley de Inmigración Selectiva, promulgada en 1845, no tuvo éxito en terrenos fiscales. Improvisaciones en la gestión dieron origen a un trato comercial entre la municipalidad y estos extranjeros, destacándose 48 lotes en la Isla Teja en la forma de franjas con orilla de río y frente a la ciudad (Guarda, 2001: 548 y 550; Bianchi, 1997: 199-201). El emplazamiento que no gozó de ubicación estratégica, tratándose solo de una isla rural, una tierra periférica, en dos años, 1850-1852, tuvo un cambio funcional. Una vez obtenidos los derechos ciudadanos solicitados al Estado, en la inicial colonización agrícola (diciembre de 1850), comenzaron a desarrollarse las profesiones de artesanos y comerciantes, lo que tuvo por consecuencia la aparición de las primeras construcciones. La oferta de terrenos se complementó con once sitios dispuestos por la Intendencia en el centro histórico (Grossbach, 2005: 218-222 y 246), el cual recibe el nombre hoy de Área Fundacional de Valdivia (Urbina et al., 2012: 5).

La evidencia del refuerzo poblacional en la ciudad (Guarda, 2001: 573) ${ }^{4}$ se manifestó en la ocupación de riberas y sus transformaciones (Guarda, 2009: 23$)^{5}$, empezando por las de la Isla Teja, retenidas hasta hoy en las fotografías, que tienen por novedad la captura de imágenes desde el río y a través del río.

\section{Apogeo industrial, comunicación fluvial y urbanismo temprano.}

La sistematización de los antecedentes históricos que hemos analizado señalan que quienes deciden no abortar la decisión de establecerse en Valdivia, en base a un capital financiero (Bernedo, 1999: 10), desarrollaron durante dos decenios, entre 1850 y 1870, una actividad

\footnotetext{
3 Un total de 2.487 habitantes fueron registrados en el censo de Ramón Picarte en 1828, uno de los momentos de menor población.

${ }^{4}$ Los registros documentales indican un total de 2.506 habitantes en $1865 ; 8.686$ en 1896; 15.229 en 1905 y 29.130 personas para el año 1920.

5 El plano topográfico de Valdivia, elaborado en 1842 por Bernardo Philippi, muestra con precisión el momento que antecede la transformación del borde fluvial, con la segunda ribera artificial.
} 
industrial y comercial a niveles uniproductores ${ }^{6}$. Esta etapa formada por talleres de manufactura de origen agrario (Almonacid, 2013: 41) dio paso a la evolución de un período de apogeo industrial en base a un "mercado agrocautivo" (Almonacid, 2013: 120, 241). Como protagonistas tuvo a cuatro familias en quienes convergieron la concentración de la propiedad del suelo de la Isla Teja: Schülcke, Anwandter, Rudloff y Hoffmann El desarrollo de conjuntos industriales en los amplios lotes (Selingardi-Sampaio, 2009: 100) ${ }^{7}$ los llamaremos pluriproductores ${ }^{8}$., Aunque en la pluriproducción persistirá una "movilidad" comercio-industria la falta general de especialización impide llamarlo "industrialización"; sin embargo, tratándose de un proceso de "proliferación de las industrias", los actores calificarán de "empresarios" debido al carácter innovador de sus acciones (Almonacid, 2013: 35, 82-84 y 142; Bernedo, 1999: 7).

Guarda califica este lapso como "un ciclo particularmente brillante entre 1880 y 1918", "prósperas décadas de 1880-1910" o la "época de oro" (Guarda, 2001: 566, 573 y 704). La consolidación del período puede ser precisada en 1873 mediante la formación de la primera organización empresarial, Unión de Valdivia, y la modernización e impacto comercial nacional de la industria de los hermanos Rudloff desde 1876 (Guarda, 2001: 696-697; Bernedo, 1999: 2329). La fabricación de insumos propios y postproducción de derivados, como todo un sistema integrado, originó la ampliación de las instalaciones fabriles derivando en complejos industriales (Bernedo, 1999, p. 41).

El sector rural constituido en negocio rentable central, con sus propios mercados, implicó la reordenación de la industria en función de las actividades silvoagropecuarias. La adquisición de predios agrícolas pasó a formar parte de la cadena industrial, como es el caso Hoffmann, junto con la creación de la Sociedad Agrícola y Ganadera de Valdivia -SAVAL-. Almonacid apunta un desequilibrio de capitales entre la industria y el sector silvoagropecuario al finalizar el s. XIX (Almonacid, 2013: 120, 241; Guarda, 2001: 679, 680-681 y 693). El comercio y servicios para la producción en predios rurales y manufactureros en la ciudad, tuvieron como consecuencia asociaciones, perfeccionamiento, diversificación, por sobre la industria (Almonacid, 2013: p. 120 y 230).

Los intereses de navegación en la hoya hidrográfica que comunica con los predios agrícolas adquiridos ríos arriba y sus afluentes, habrían generado el uso intensivo de la cuenca. La continuidad de edificaciones que los asentamientos industriales y comerciales otorgaron al frente del cauce fluvial, encontraron un desequilibrio en la gestión de su desarrollo originándose parte importante del fin de nuevas expansiones.

Desastres naturales, incendios, crisis en el comercio internacional y vulnerabilidades geopolíticas ${ }^{9}$, cuentan como un conjunto de factores que también debilitaron los asentamientos industriales (Almonacid, 2013: 9, 56 y 78; Guarda, 2001: 672, 694 y 709; Bernedo, 1999: 37) ${ }^{10}$. La decadencia con consecuencias físicas tuvo lugar desde 1960 a 2013, entre el terremoto y la

\footnotetext{
${ }^{6}$ Rubros uniproductores: especializada en desarrollar un producto principal, que se abastece de insumos y servicios de terceros, y desecha o vende material sobrante originado en sus procesos de fabricación.

${ }^{7}$ La tesis geográfica industrial de este autor considera la estructura de aglomeración, tramas extendidas y condensadas, como un conjunto especializado e indisociable que confiere un marco temporal e histórico.

8 Rubros pluriproductores: se especializa en desarrolla insumos y servicios para el producto principal, y subproductos derivados del producto principal, ampliando así los rubros fabriles y de servicios.

9 Maquinarias y repuestos impedidos de arribar durante la guerra, entre los años 1914-1917, especialmente "el bloqueo económico a las empresas con propietarios de apellido alemán, inscritos en la Lista Negra" durante la segunda guerra mundial, entre los años 1939 y 1945.

${ }^{10}$ Almonacid enuncia un "techo hacia 1914" para el desarrollo de las industrias de Valdivia, el cual involucra la paralización del crecimiento de astilleros junto con, el perjuicio de la apertura del canal de Panamá para los Armadores de Valdivia y las sanciones a industrias de alemanes durante la primera guerra mundial y la lista negra a capitales alemanes, entre 1940 y 1946
} 
demolición de la infraestructura de SAIC Hoffmann en Isla Teja, que aseguró la completa desaparición de las estructuras de inicio del s. XX, heredera de Hoffmann Hnos. del s. XIX. Únicamente dos ejemplares de ruinas -Rudloff y Anwandter/CCU- (Fig. 2a-c)- quedaron en toda esa ribera que se conoció a partir de 1873/1876.
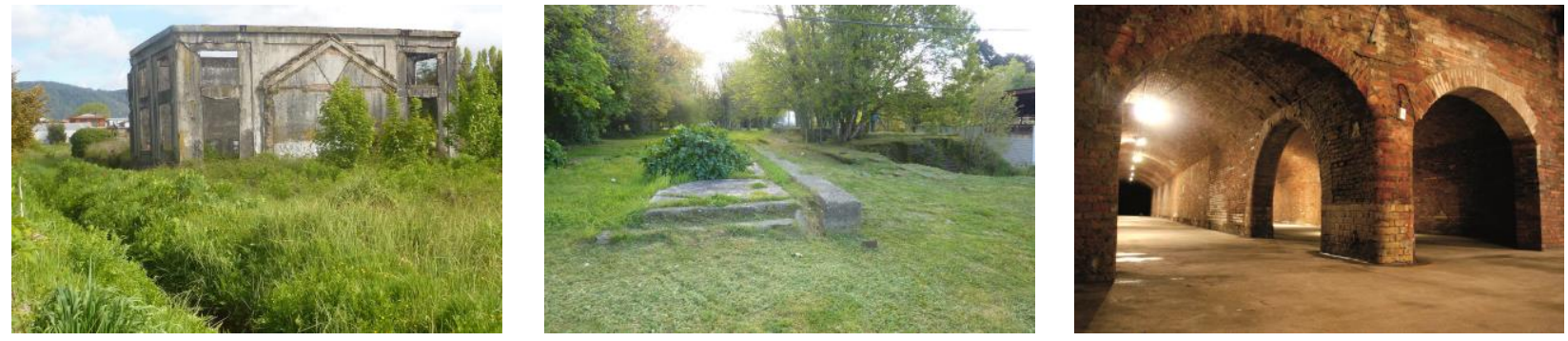

Fig. 2 Ruinas remanentes al año 2014

a. (Izquierda) Fábrica Rudloff, Isla Teja

b. (Centro) Piso zócalo de la cervecería Anwandter/CCU, Isla Teja

c. (Derecha) Subterráneo de la cervecería Anwandter/CCU

Fuente: Colección Gerardo Saelzer.

\section{Escalas urbanizadoras y experimentación arquitectónica}

Los manufactureros, comerciantes y agricultores ejercen la actividad industrial ascendiendo de artesanos a industriales, y desde pequeños a grandes industriales (Almonacid, 2013: 86 y 141). El repertorio fabril manufacturero publicado permite reconocer escalas generales de producción durante el apogeo industrial; sin embargo no contamos con descripciones de los procesos productivos y de comercialización; es decir, no es posible reconstruir la complejidad organizacional de las operaciones y su impacto en el espacio, dada la ausencia de datos cruciales sobre infraestructura, traslados, y comunicaciones.

\subsection{Escalas arquitectónicas de transformación urbana.}

En la etapa comprendida entre 1850 y 1873/1876, el Área Fundacional fue afectada por oferta de sitios (Grossbach, 2005: 218-222 y 246) y comercio como se identifica en los primeros registros fotográficos (Borneck e Izquierdo, 2009: 15, 19, 20, 44, 55, 65; Guarda, 2001: 590 y 684). Construcciones de viviendas y de instalaciones uniproductoras generaron una transformación arquitectónica: en un inicio se trata de edificaciones aisladas, como se ve en las fuentes visuales, que se ubican entre las edificaciones coloniales del Área Fundacional. Conjuntos de arquitecturas del nuevo estado surgen además cerca de la ribera en la Isla Teja, en medio de condiciones naturales así como también en otros lugares de la cuenca (Fig. 3a).

El segundo momento, caracterizado por la pluriproducción, también muestra la expansión de la ciudad a lo largo de las riberas, mediante viviendas, comercio, así como por conjuntos industriales. La fuerza geográfica de los emplazamientos y de las edificaciones de mayor tamaño, proveen nuevas escalas, que determinan impactos urbanos y paisajísticos que no se habían planificado (Guarda, 2001: 681) ${ }^{11}$ (Fig. 3b).

Los conjuntos industriales que compusieron producción centralizada en un solo recinto (Bernedo, 1999: 6), resolvieron en su espacio predial los accesos y la comercialización en el rio, adquiriendo la condición de borde fluvial urbano (Fig. 4 y Fig. 5a-b). La mayor expresión se encuentra en los

11 Guarda, citando a Blancpain, señala respecto de los conjuntos construidos en los predios rurales (que, entre otros, podrían tratarse de la Isla Teja), están "emplazados en lugares eminentes y dentro de los cánones del neoclasicismo, sus hermosas casas de campo se edifican junto a monumentales galpones, bodegas y 'campanarios' de madera, rodeándose de jardines y parques". 
conjuntos industriales vecinos entre sí, Anwandter (Maltería), Rudloff y Hoffmann, generándose un acoplamiento de muelles. Ellos posibilitan el eventual traslado o tránsito entre industrias (Fig. 6, Fig. 7, Fig. 8), articulando el paralelo a la ribera opuesta, de la costanera del Área Fundacional.
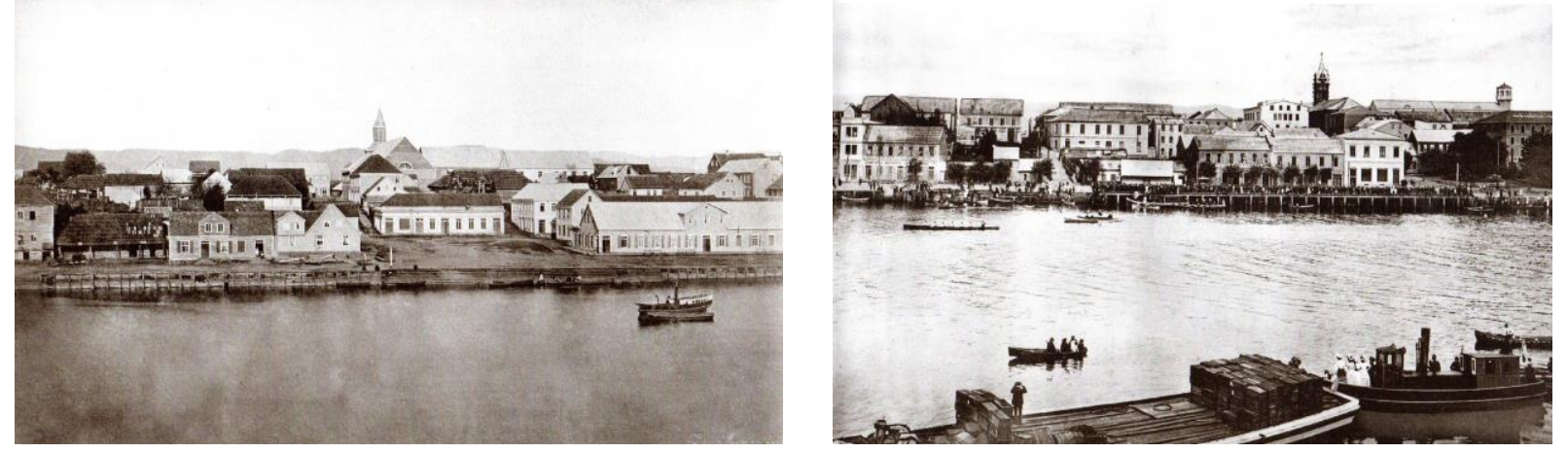

Fig. 3 Proceso urbano del borde fluvial, caso Costanera-Centro de Valdivia

a. (Izquierda) Borde fluvial del Área Fundacional de Valdivia, ca. 1871

b. (Derecha) Borde fluvial del Área Fundacional de Valdivia, desde Isla Teja, ca. 1909

Fuente: Borneck e Izquierdo, 2009.

La actividad industrial que implementará la producción en línea, requirió edificios, patios y transporte que derivaron en la construcción de embarcaderos. Las tipologías arquitectónicas se hicieron evidentes en la ciudad mediante el cambio de volumen de las infraestructuras, aptos para la modernización (fuentes de energía a vapor) más la centralización de la producción. Las edificaciones se observaron desde el Área Fundacional de Valdivia, con creciente impacto en su visualización panorámica. Las industrias, almacenes y viviendas, mediante las ampliaciones intervinieron la ribera, transformando el estado periurbano en paisaje urbano.

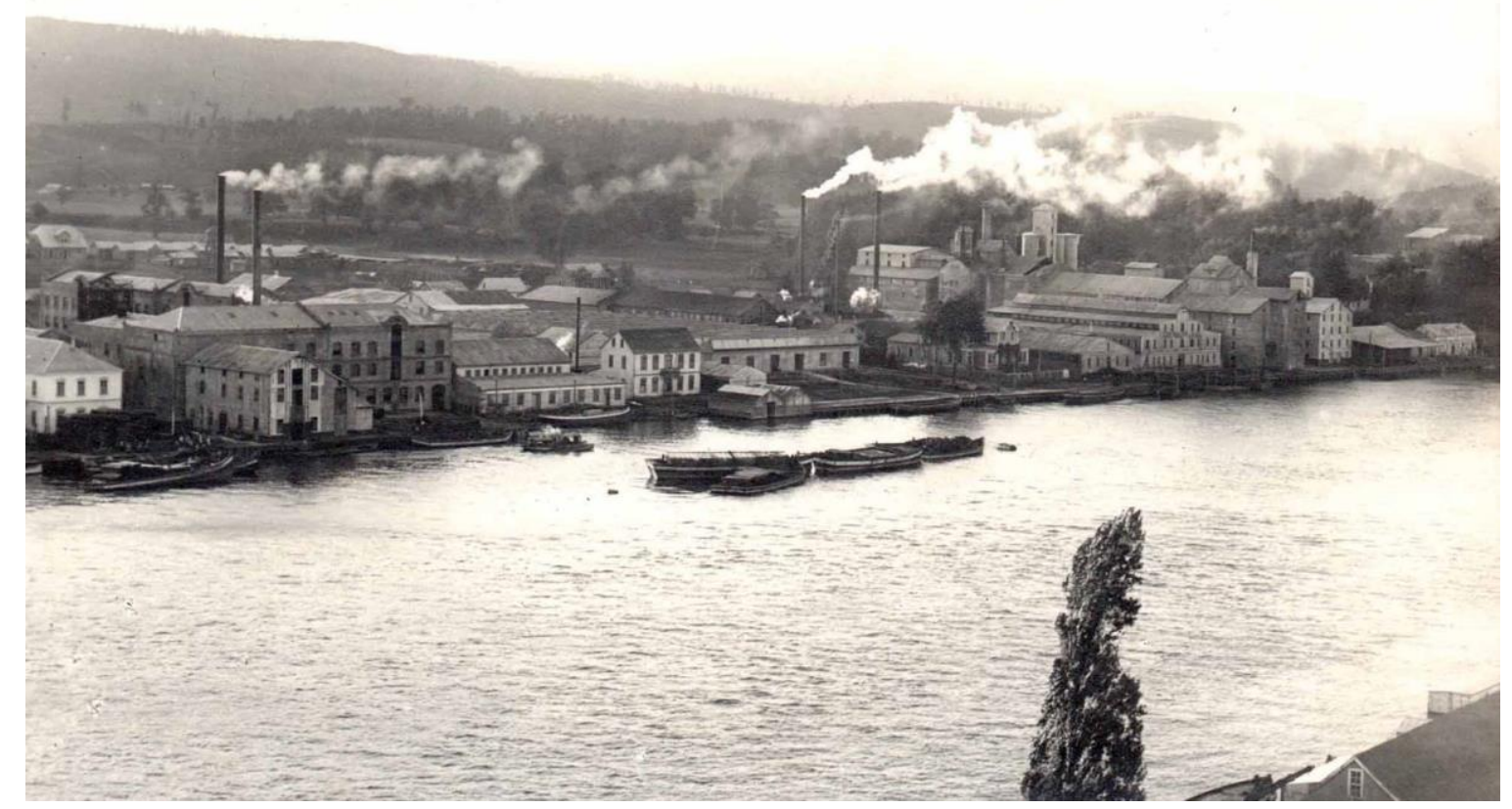

Fig. 4 Industrias Hoffman (Destilería), Rudloff (Calzados) y Anwandter (Maltería), Isla Teja, s/f. Fuente: Colección Gerardo Saelzer. 
El primer momento de operación arquitectónica que modifica escalas y estilos de construcción, adaptó materiales de la zona, atisbándose por ello una tipología. El segundo momento cobra rasgos de urbanización pues comienza a alterar el territorio en virtud de los emplazamientos estratégicos, las comunicaciones y traslados, y la aplicación de nuevas estrategias de seguridad en la construcción, referidas por el elenco de aseguradoras en 1915 (Guarda, 2001: 709). Como se verifica en el plano municipal de $1907^{12}$, se han introducido de esta manera nuevos límites, que extienden a Valdivia fuera del área fundacional -de la limitación de los hualves que dibujaba la vieja cerca de Duce, además de incluir como casco urbano esos terrenos de inundación y riberas del río hasta entonces desvinculadas de la ciudad ${ }^{13}$.

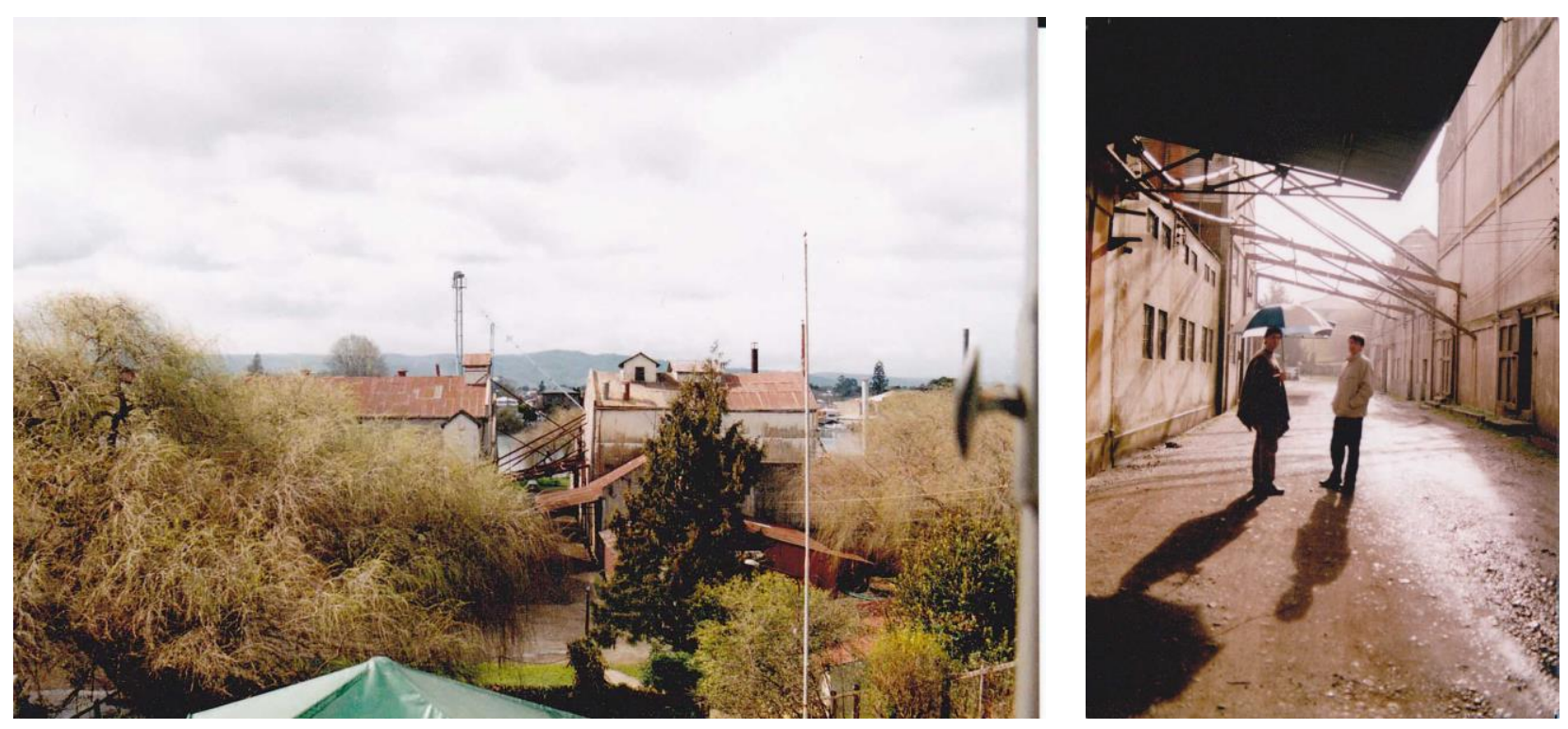

Fig. 5 Infraestructura remanente 1961-2012, caso Hoffmann

a. (Izquierda) Panorámica complejo industrial Hoffman, previa demolición, ca. 2012

b. (Derecha) Vista interior complejo industrial Hoffman, previa demolición, ca. 2012 Fuente: Colección Gerardo Saelzer.

Así como la primera producción reemplazará escalas y formas en las casas de adaptación colonial en madera, la evolución posterior contempló el desarrollo de estilos (Phillippi, 1950: 16) y una fecunda relación con el paisaje. Igual procedimiento se atisba en la producción de edificios industriales, adaptación y generación de estilos aunque de manera más incipiente y tardía que las casas. Finalmente, el fenómeno de "colonia residente otorgando una visibilidad" con consecuencias de identidad y creación de significado ${ }^{14}$, contó en su origen con un espacio aislado, circunscrito a su área fundacional, de escasa población, y riberas en condiciones rurales (Almonacid, 2013: 9, 33-35 y 243-286) En dicha relación industria-tierra, el medio rural en que se desenvuelve la industria competirá con los capitales de los industriales. La relación entre inmigración, apogeo industrial y extensión panorámica de la ciudad, vigente durante más de un siglo, constituye un caso territorial excepcional para la planificación territorial. Con diversos acentos y atractivos se lo capturó en las fotografías a lo largo de las riberas.

\footnotetext{
12 "Plano Topográfico de Valdivia" dibujado por el ingeniero -radicado en la cervecería Anwandter-, Juan Antoine (Guarda, 2009, plano n²0: 27).

13 Por ejemplo, Carlos Cousiño/Plaza Berlín y zona entre Aníbal Pinto y General Lagos.

14 Véase la propuesta analítica formulada por Benedict Anderson (Pinto y Valdivia, 2009: 274-275).
} 


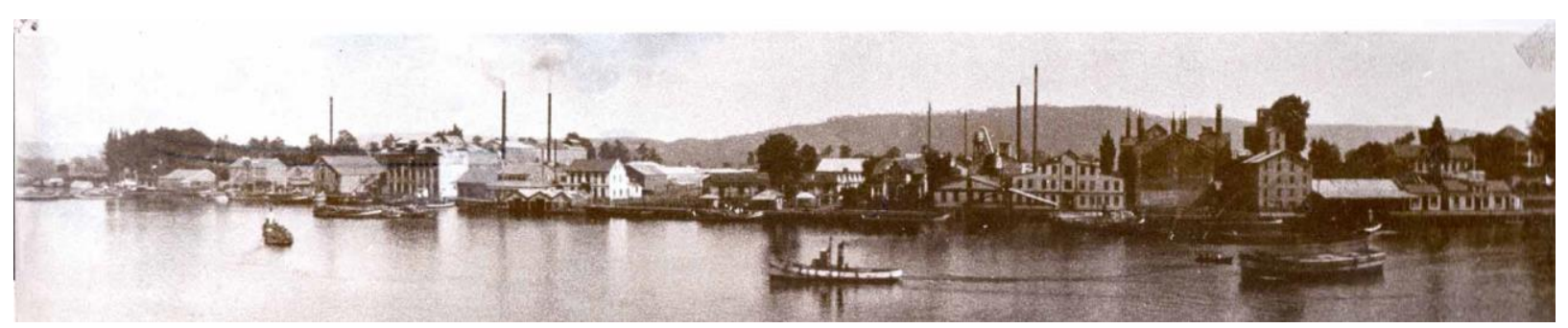

Fig. 6 Complejos industriales Hoffmann, Rudloff y Anwandter (maltería), ca. 1900. Fuente: Colección Gerardo Saelzer.

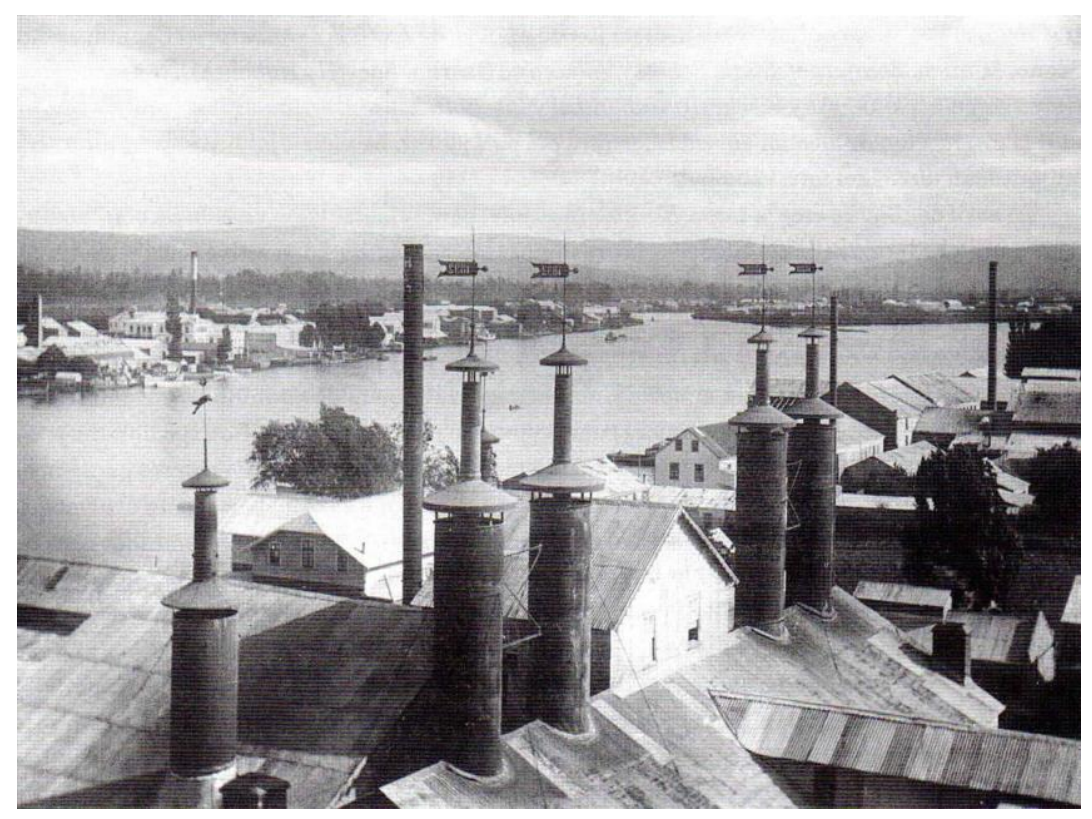

Fig. 7 Vista desde chimeneas Cervecería Anwandter/CCU, Isla Teja, ca. 1892. Fuente: Archivo Fotográfico, Dirección Museológica, Universidad Austral de Chile.

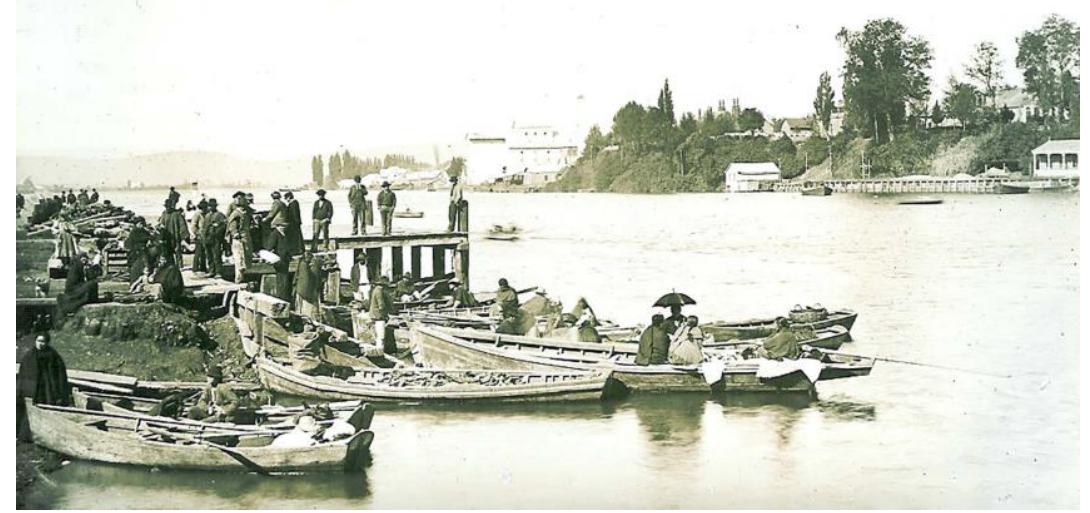

Fig. 8 Borde fluvial Área Fundacional de Valdivia,, ca. 1900 Fuente: Colección Gerardo Saelzer. 


\subsection{Tipologías y procedimientos materiales.}

Aunque faltan elementos de juicio para precisar el desarrollo material, en un inicio del apogeo industrial observamos únicamente el empleo de madera, con la que se repetirán modelos de arquitectura importados (Muñoz, 2005: 25-26 y 29). Luego se visualiza el metal como material de revestimiento dispuesto sobre la madera y también sobre el ladrillo que ocupa un lugar tempranamente (Muñoz, 2005: 30; Aranda et al., 1920: 709)15. El hormigón aparece en combinación con acero durante la reconstrucción desde 1910, sin abandonar completamente la combinación con madera. Guarda señala que se trata de "... edificios de estructura mixta de hormigón y perfiles de hierro, levantados en la década de 1910", los cuales aprovecharon "... la oportunidad que ofreció la destrucción de 1909" para levantar nuevos edificios marcados por "... el modernismo" (Guarda, 2001: 580, 585 y 693). El astillero de la firma Schuller proporcionó la draga y consecuentemente los áridos, empresario que también se dedica al abastecimiento de acero para la construcción (Aranda et al., 1920: 416 y 417). Suponemos que escala e imagen responden a los materiales de edificación disponibles y a modelos adoptados desde las regiones de origen de los inmigrantes. La selección de estilos y materiales tuvo como consecuencia una experimentación estilística, la modificación de procesos de construcción y el traspaso de conocimientos.

La conexión ininterrumpida de varias generaciones con el lugar de origen de sus antecesores, nos remite a la búsqueda de referentes y situaciones paralelas en Alemania a partir de su ubicación geográfica y emplazamiento: 1.) almacenes industriales y portuarios (ca. 1838-1900) del río Havel en Potsdam (Blohmayer, 2002: 4-15, 28-32) ${ }^{16}$-circuito de Carlos Anwandter, vocero de los inmigrantes e industrial pionero en Valdivia- y 2.) los almacenes industriales y portuarios (1904) del río Mein en Würzburg (Martin, 2002: 12-17): estructuras de madera y fachadas contenedoras en bloques, ladrillos, piedras (lajas de esquisto) u hormigón, manifiestan la oportunidad local de construcción.

En suma, alturas trazadas como varias plantas que sin embargo son interiores continuos, tamaños que expresan volúmenes de comercialización, desaparición de las morfologías cambiadas por suelos artificiales (Guarda, 2001: 580) -plataformas y muelles- y la proximidad al río, van sustentando un modelo común de colonización de riberas hasta la orilla misma, abordada hoy como tipología de ciudades portuarias fluviales. En peligro de desaparición, la transformación del suelo de ribera, industria, y ciudad, arriban a la integración puerto-ciudad en consonancia con procesos similares que ocurren globalmente (Wilson, 2002: 11-15), y del cual Valdivia no es una excepción sino quizás uno de los casos más dramáticos que se puedan imaginar.

\section{Extensión de la ciudad}

\subsection{Ribera, primeras propiedades y operaciones territoriales.}

En el proceso de ocupación de los bordes de los ríos Calle-Calle y Valdivia, en orden geográfico cuenta primero la playa adyacente al "área fundacional" de la ciudad, al que se le instala la costanera; la extensiones hacia Miraflores y hacia Collico; los asentamientos en la Isla Teja y en las Ánimas. La intervención territorial periférica se encargó de ampliar y desarrollar el Área Fundacional. Monográficamente la cartografía histórica (Plano 1) da cuenta de cómo se centró el curso fluvial (Lámina 1) y se manifestó la aparición de las riberas (Plano 2, Plano 3, Plano 4).

15 Pueden mencionarse la fábrica de ladrillos de alemanes: König desde 1854 y Geywitz y Körnig desde 1889. Aquello además queda refrendado por los vestigios fotografiados en SAIC Hoffmann y otros aun remanentes en el emplazamiento de la cervecería Anwandter/CCU.

16 Abordados en el concurso del Master Plan Kulturspeicher de 2001. 
Revista de Urbanismo N³3 - Julio - Diciembre de 2015 Departamento de Urbanismo - FAU - Universidad de Chile

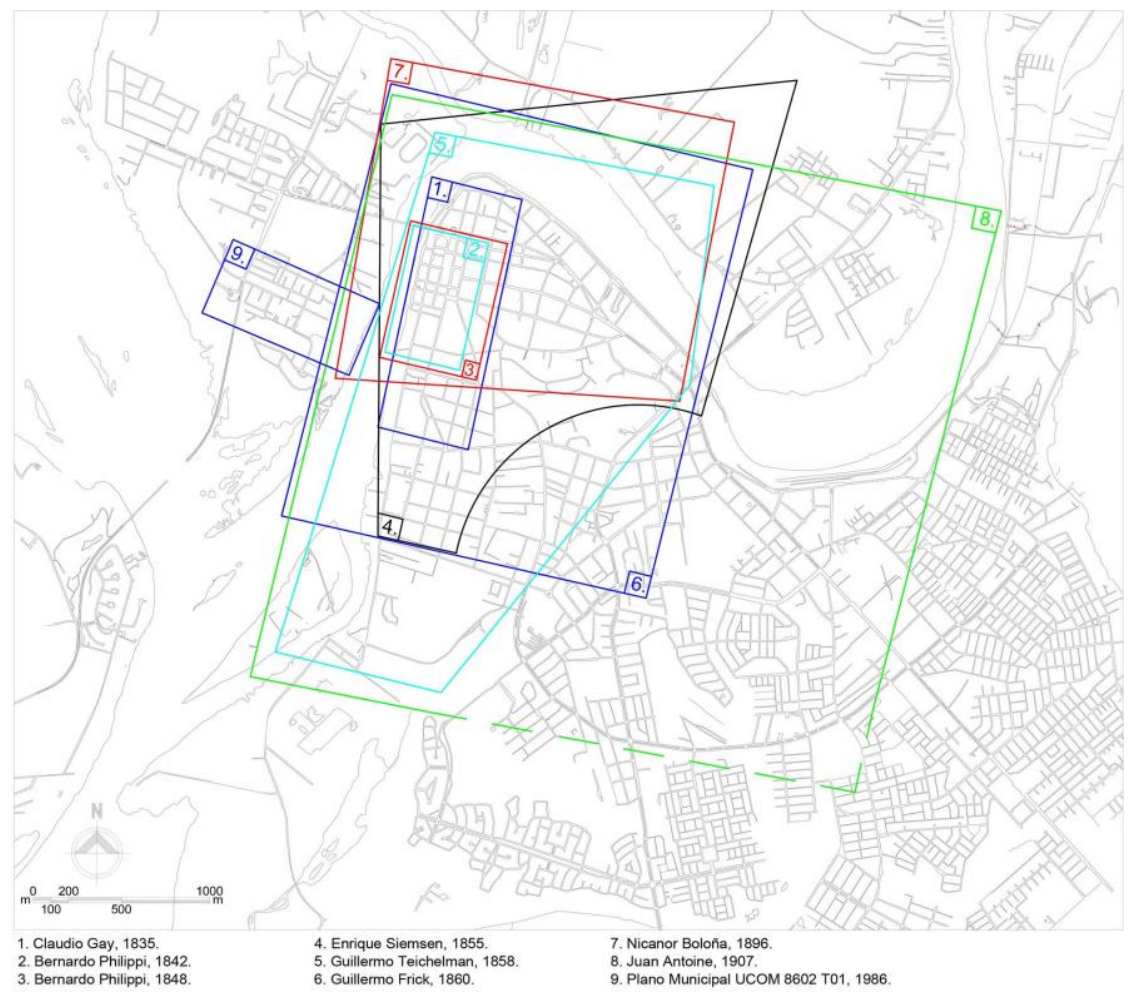

Plano 1 Encuadre de la cartografía histórica para la ciudad de Valdivia, ca. 1835-1986. Fuente: Elaboración propia

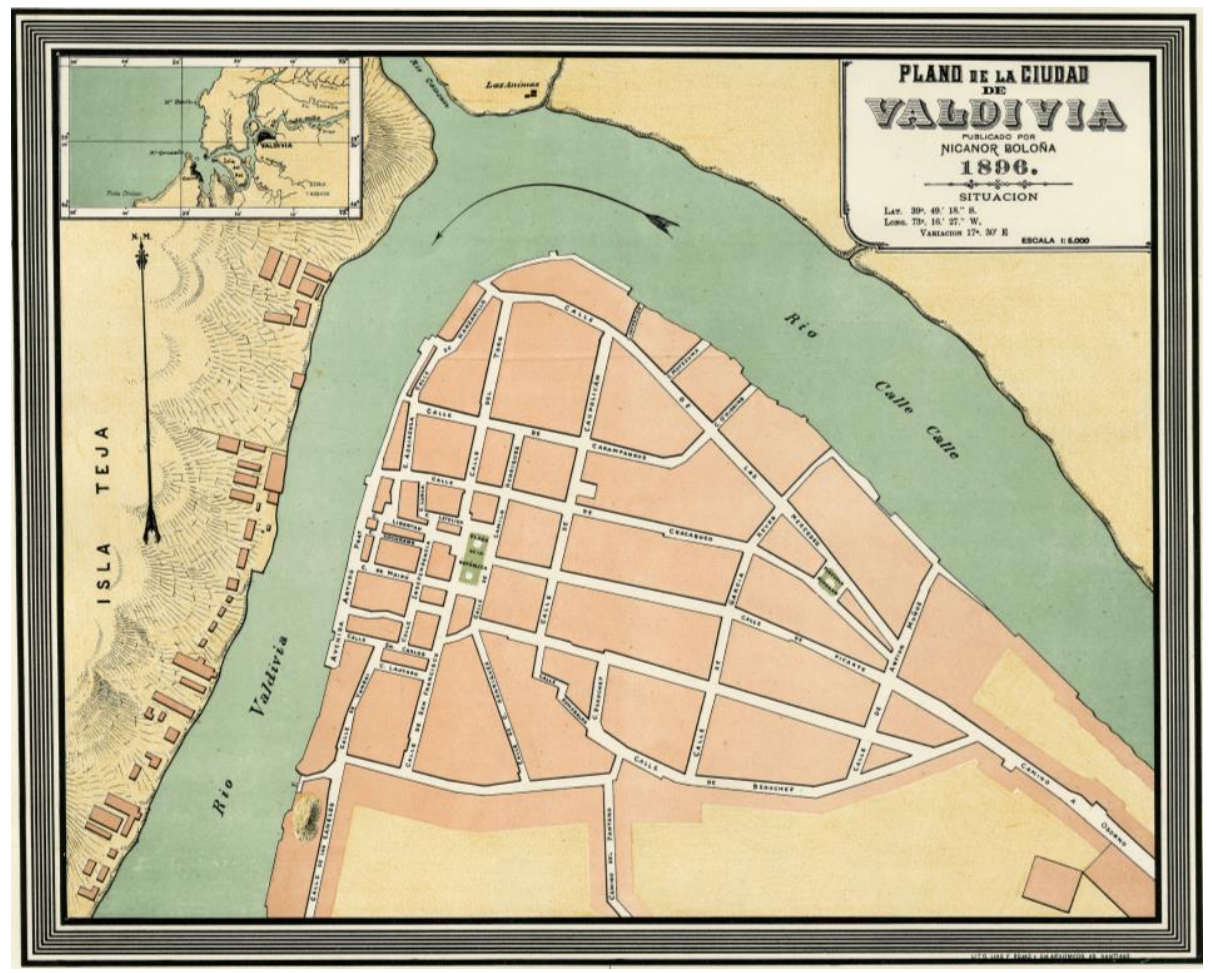

Lámina 1 Plano de Valdivia, Nicanor Boloña, 1896. Fuente: Mapoteca Biblioteca Nacional de Chile. 
Papel connotado ocupa la Isla Teja o de Valenzuela, propiedad común de los habitantes desde 1741 y desde 1842 de la ciudad, como corporación -municipal-, vendida íntegramente a las familias alemanas en forma de lotes individuales (Bianchi, 1997: 199-201). Como resultado selló desde 1852 su incorporación urbana. A partir de las primeras edificaciones en los bordes de la Isla Teja, cambiará el sentido de orientación de la ciudad, desde las mesetas entre hualves, según se desprende de los planos Siemsen, Teichelmann y Frick, hacia mesetas sobre el río de frente a la ciudad, y luego la totalidad de los bordes fluviales.

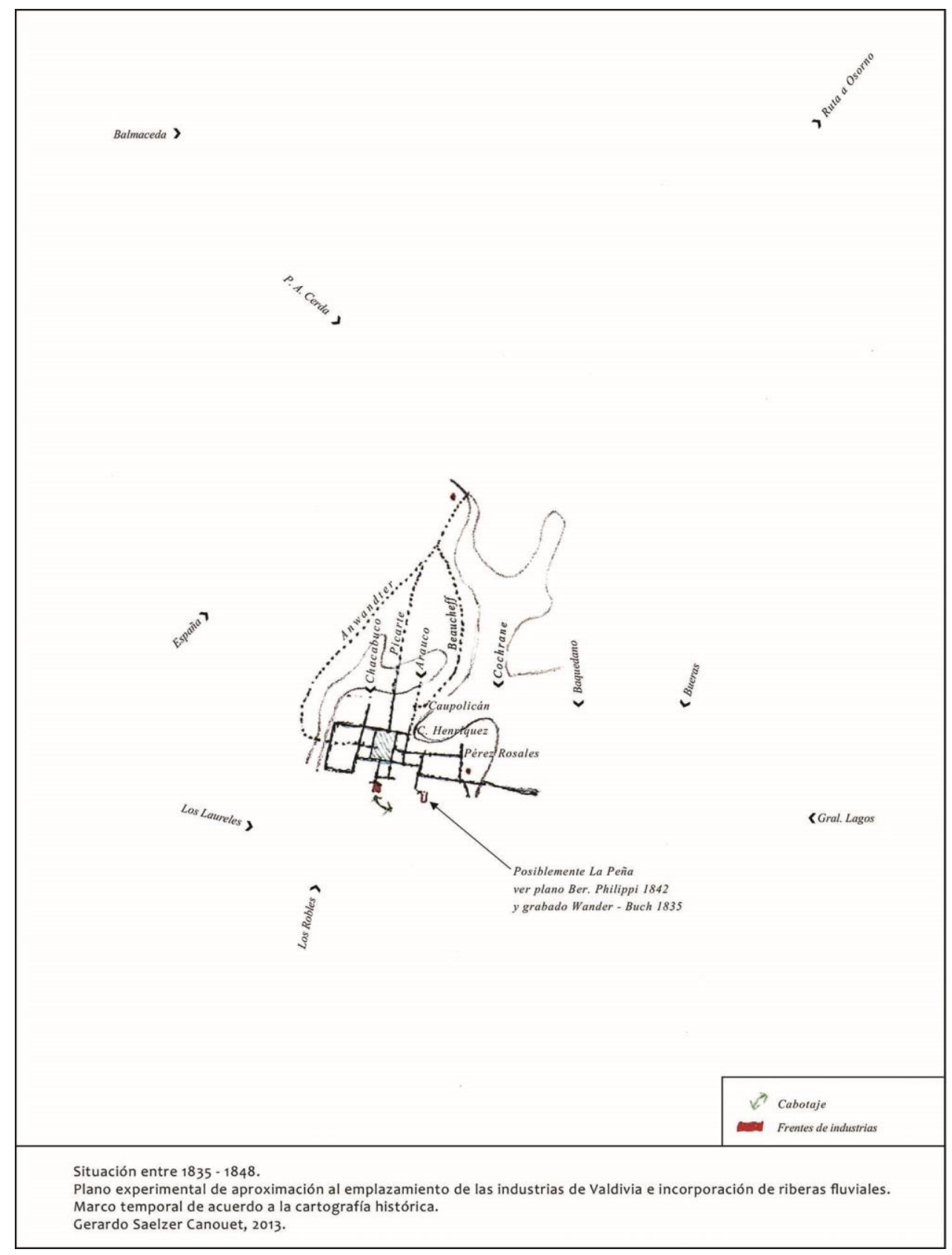

Plano 2 Esquema territorio urbano de Valdivia, ca. 1835-1848. Fuente: Elaboración propia 


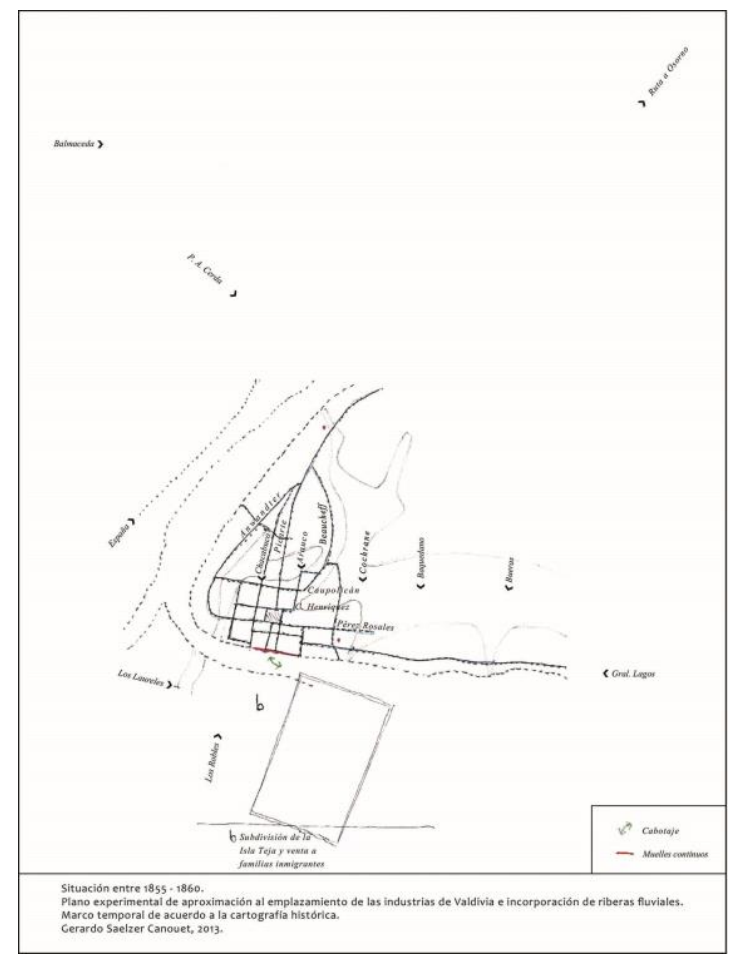

Plano 3 Esquema territorio urbano de Valdivia, ca. 1855-1860. Fuente: Elaboración propia

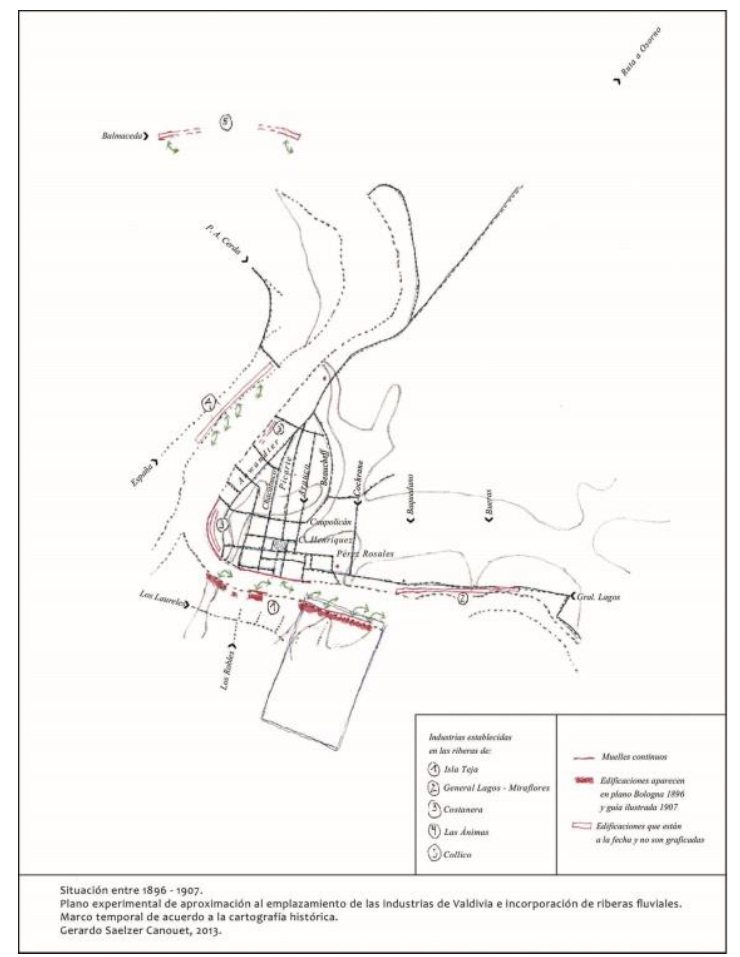

Plano 4 Esquema territorio urbano de Valdivia, ca. 1896-1907. Fuente: Elaboración propia 
Así como los referentes citados aportan una tipología con características a las que, aparentemente, Valdivia se vinculó, adicionalmente se constata que la conformación predial evolucionó hacia la aparición de un conjunto continuo de edificaciones asociado a un golpe de vista (Treutler, 1958: 288) y lo que éste comunica: la significancia de estar dentro de una ciudad y en este caso además dentro de una condición geográfica plenamente identificable.

\subsection{Dimensión productiva, social e inter comunicación}

La estrategia industrial se conformó a la capacidad fisiográfica de la ciudad y dió origen a la comunicación fluvial y marítima combinadas (Almonacid, 2013: 120 y 141) ${ }^{17}$. Esta estrategia se comprende junto a entidades comerciales y servicios con asiento director en la misma ciudad (Guarda, 2001: 710), que originaron en consecuencia el desarrollo local de sedes gremiales y de fomento, iniciativas de beneficencia, residencias de jerarquía. En suma, la creación de una burguesía alojó el sustento de la invisible variable del poder con que se construirán las instituciones (Tabla 1), reponiéndose Valdivia de las debilidades que la caracterizan durante el lapso 1820-1850 (Bernedo, 1999: 39-40).

La creación de empresas de servicios navieros y de transporte fluvial (Bernedo, 1999: 35), además de densificar de tráfico de embarcaciones, tejió formalmente la ciudad a través del río, que se observa como vía comercial y escenario productivo. Cada industria constituyó en terreno una estrategia respecto al río, urbanizándolo en gestos de carácter arquitectónico, umbral que a la vez tendrá connotación en la ciudad. Industria y vivienda pasan a ser consumidoras de mayores espacios, a la vez constructoras de extensiones panorámicas que posibilitaron el sentido de colectividad irradiadas por las fotografías, que dan cuenta de un escenario fluvial de alta densidad también en actividades de recreo y festejos.

La incorporación de Valdivia al comercio portuario y la vinculación permanente con Valparaíso desde 1851, mediante servicio regular de cabotaje y pasajeros, además de la confluencia de la práctica del comercio liberal e integración globalizante, lleva a precisar que se trata de dos ciudades que desde cierta generación urbana espontánea (Álvarez y Navarro, 1994) desarrollaron singularidades geográficas y comerciales que las distinguen de las ciudades programadas económica y políticamente que pueblan la matriz longitudinal de Chile (Lorenzo, 1986: 23 y 68). Se adquiere consonancia con el proceso comercial, industrial, burgués y urbano que viven ambas ciudades; la trayectoria de Valdivia a la par de Valparaíso, permite repasar el significado particular del proceso urbanizador para tener costa continua, libre de obstáculos (Saelzer, 2014).

17 "... capaces de organizar individual y familiarmente sus empresas [...] capacidad de asociarse económicamente [...] la tendencia a la asociación [...] se extendió al ámbito de la defensa de los intereses gremiales, tanto a nivel nacional como local" (Bernedo, 1999: 38). 
Revista de Urbanismo N³3 - Julio - Diciembre de 2015 Departamento de Urbanismo - FAU - Universidad de Chile

Tabla 1 Asociaciones de representación en Valdivia (1872-1957).

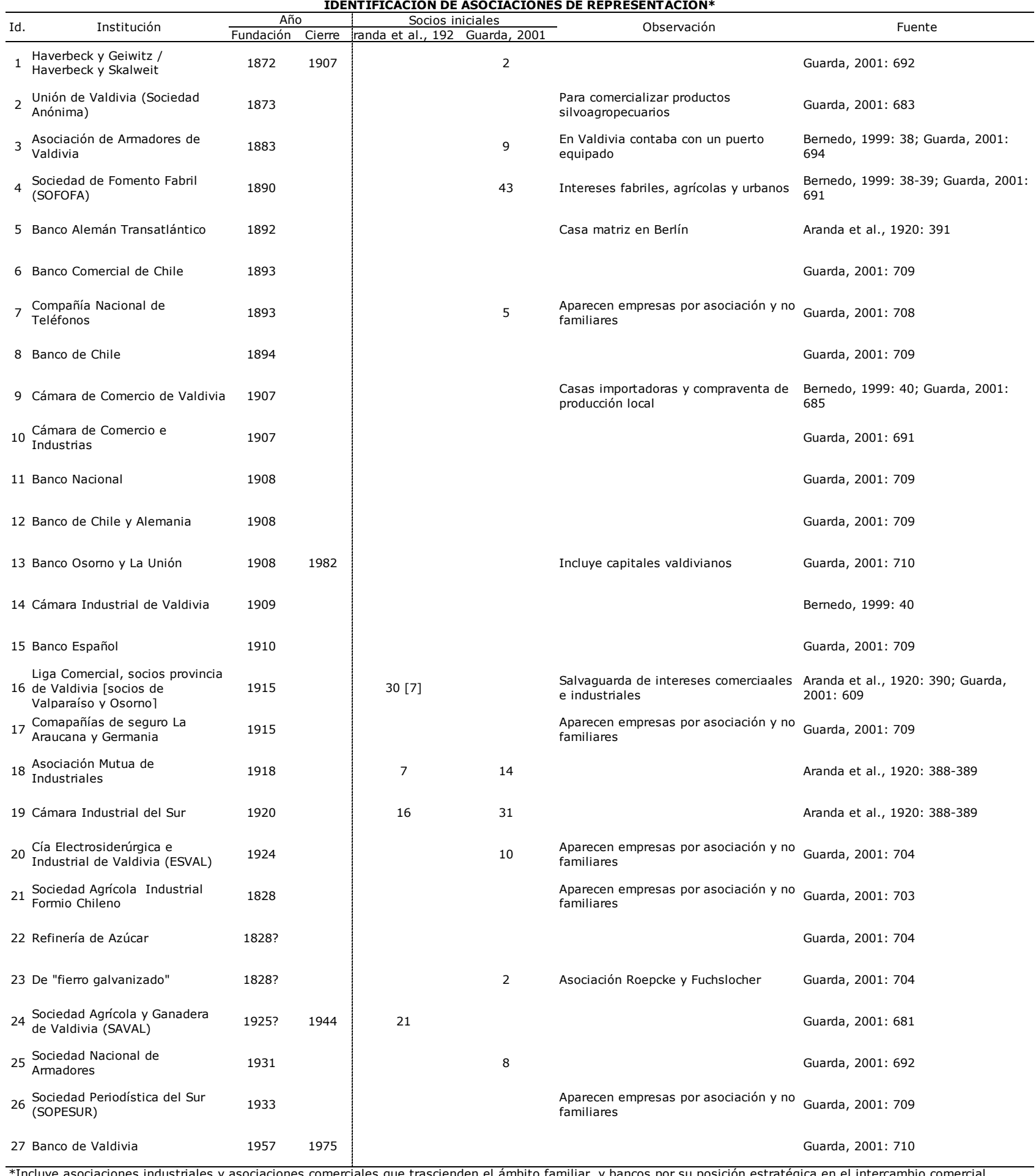

Fuente: Elaboración propia 
Revista de Urbanismo N³3 - Julio - Diciembre de 2015

\section{Operaciones constructivas, formas y complejidad del espacio paisajístico.}

La observación de las imágenes en Aranda y Guarda y el levantamiento del proceso industrial de las riberas (plano 4 y 5 ) en concordancia con el marco temporal que cubren estas ediciones, permiten efectuar un barrido de tipologías del galpón, silos, chimeneas, fachadas, ventanas, tejados, patios, muelles, alturas, anchos, volúmenes, distancias al río, adopción del relieve (Aranda et al., 1920: 392, 394, 408-414, 416-419, 420, 426-427, 438, 440, 441, 465 y 493 ; Guarda, 2001: 696, 699, 702 y 930).

En consecuencia, durante la segunda etapa industrial de Valdivia, aquella caracterizada por lo que hemos llamado "rubros pluriproductores", estamos ante la organización de plantas industriales, procesos en línea, almacenajes, faenas de carga y descarga. De esta etapa se deriva la composición de los elementos arquitectónicos transformados en fotografía: sombras, luminosidad, prestancia; materialidad de la madera, del ladrillo, metales y hormigón. Para profundizar, cabe preguntarse por las dinámicas sociales y económicas presentes al momento de adoptar recursos estilísticos y funcionales, materiales alternativos a los empleados en los arquetipos y adecuaciones a los referentes y situaciones paralelas. El conjunto de edificios que se integran al espacio y desarrollan un sentido de organización, abarcan desde el tejido económico hasta la imagen pública de los conjuntos, más la experiencia visual, social y la identificación con el espacio fluvial que representa a los ciudadanos. La construcción de infraestructura industrial en Valdivia se desplegó de frente al "área fundacional", que mantiene su condición de centro de la ciudad, lo que permite identificar un momento en que la ciudad comenzó a mirar a sí misma mediante autorreferencias espaciales tales como: Valdivia-Isla Teja, Valdivia-Las Animas, Valdivia-Las Animas-Collico, Isla Teja-Miraflores (Plano 5).

A través de las imágenes fotográficas obtenidas desde los tejados y chimeneas, se comunica un sentido de pujanza y esplendor. Esa contemplación adquiere el atributo espacial que se abre como oportunidad por primera vez: la altura y la integración paisajística (Fig. 7). La integración se observa a través de muelles que sostienen un tráfico entre tierra y río, y a lo largo de los muelles, como los que unieron en la Isla Teja desde la industria Hoffmann hasta la industria Rudloff (Fig. 7 y Fig. 8), y en el Área Fundacional desde la aduana hasta el embarcadero llamado de La Peña (Fig. 9). Las insfraestructuras constituyeron sentidos paralelos y sentidos transversales de desplazamiento en respuesta a diversas organizaciones logísticas caracterizadas por una matriz entrada-salida entre los lugares de producción y el río. Las interrelaciones originaron una grilla formada por un gran largo de ribera y un breve ancho de la circulación entre el lecho fluvial y tierra firme.

La aparición de la línea recta como estrategia entre las áreas industriales y los procesos productivos, tiene una manifestación en la producción, convivencia y el comando empresarial. Caso final heredado hasta hace poco, la industria SAIC Hoffmann que desde el muelle a la gerencia en lo alto de una colina atravesó visual y peatonalmente las instalaciones, coincidiendo con el patio central que organizó los dos bloques de pluriproducción (Fig. 10). 


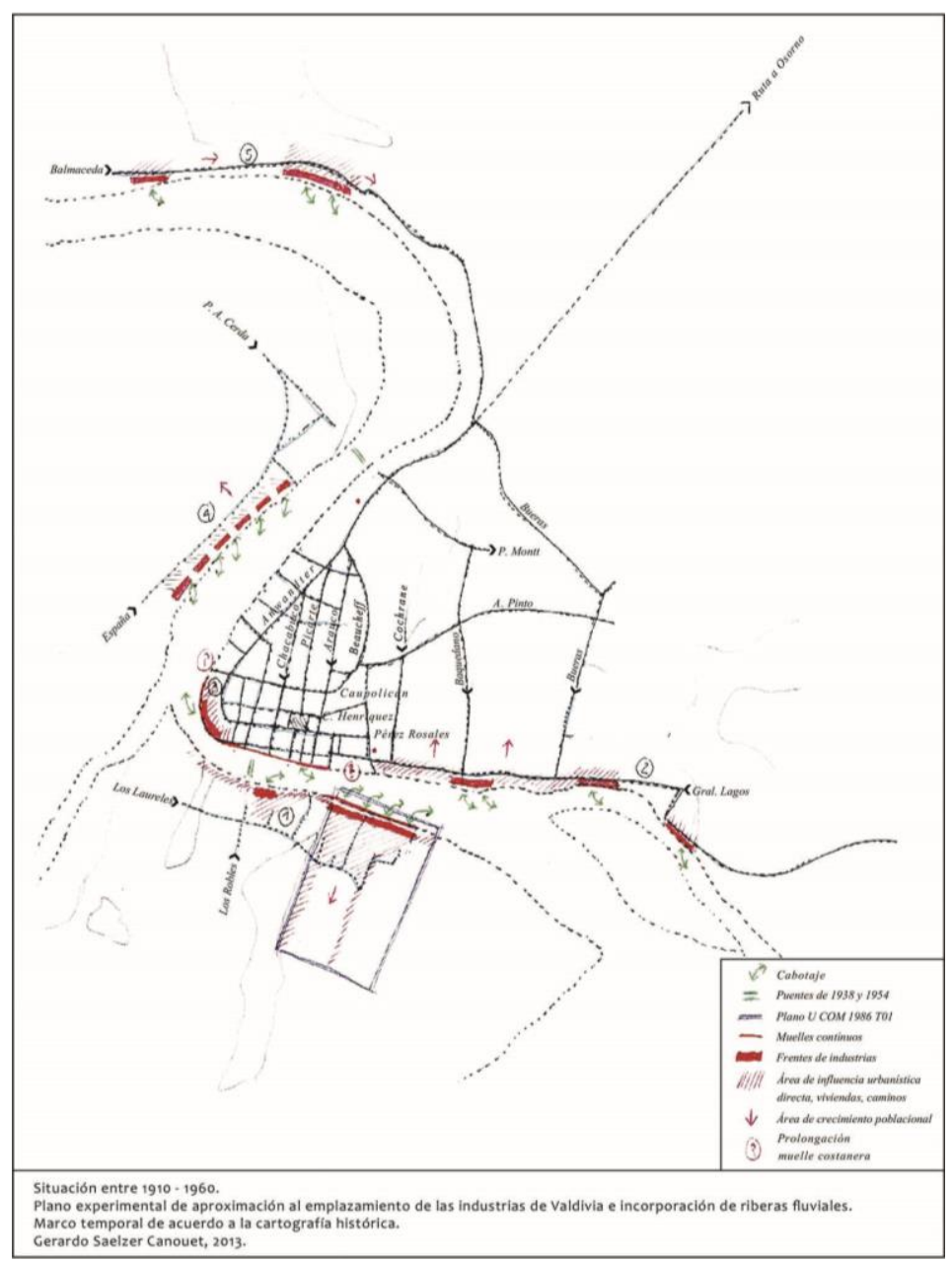

Plano 5 Esquema territorio urbano de Valdivia, ca. 1910-1960. Fuente: Elaboración propia

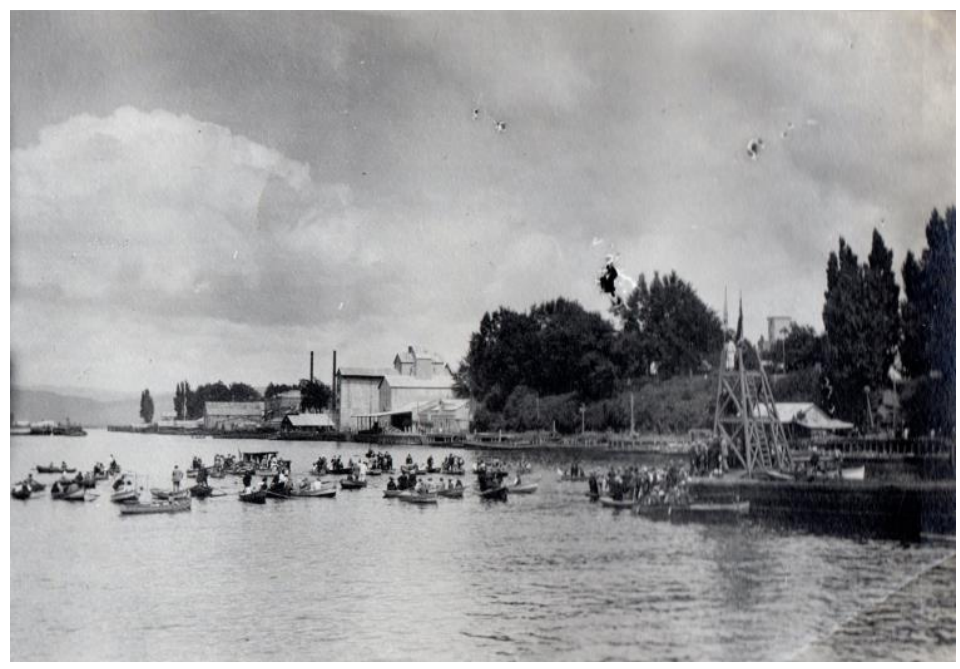

Fig. 9 Borde fluvial en la Isla Teja, hacia el sur, s/f. Fuente: Colección Gerardo Saelzer. 


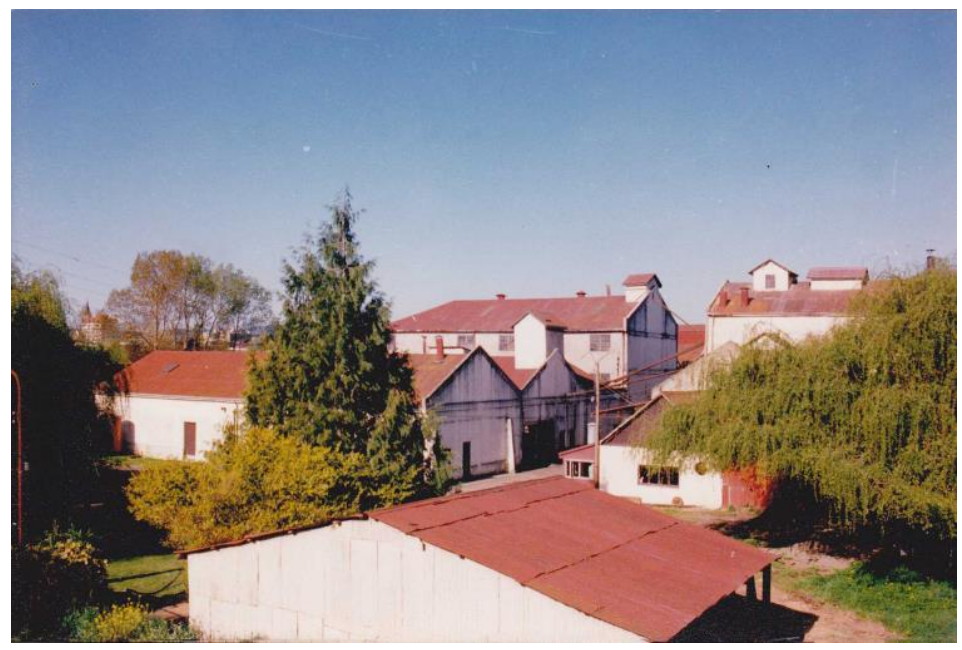

Fig. 10 Panorámica complejo industrial Hoffman, previa demolición, ca. 2012. Fuente: Colección Gerardo Saelzer.

Tres etapas del complejo o conjunto industrial Hoffman, desde sus inicios en la década de 1870 hasta su total desmantelamiento en el año 2012, pueden ser apreciados en la serie de planimetrías (Plano 6, Plano 7,Plano 8,Plano 9 yPlano 10). En lo sucesivo, se requiere ampliar el estudio de estas etapas a otros complejos industriales de Valdivia, para verificar comportamientos arquitectónicos análogos o disímiles.

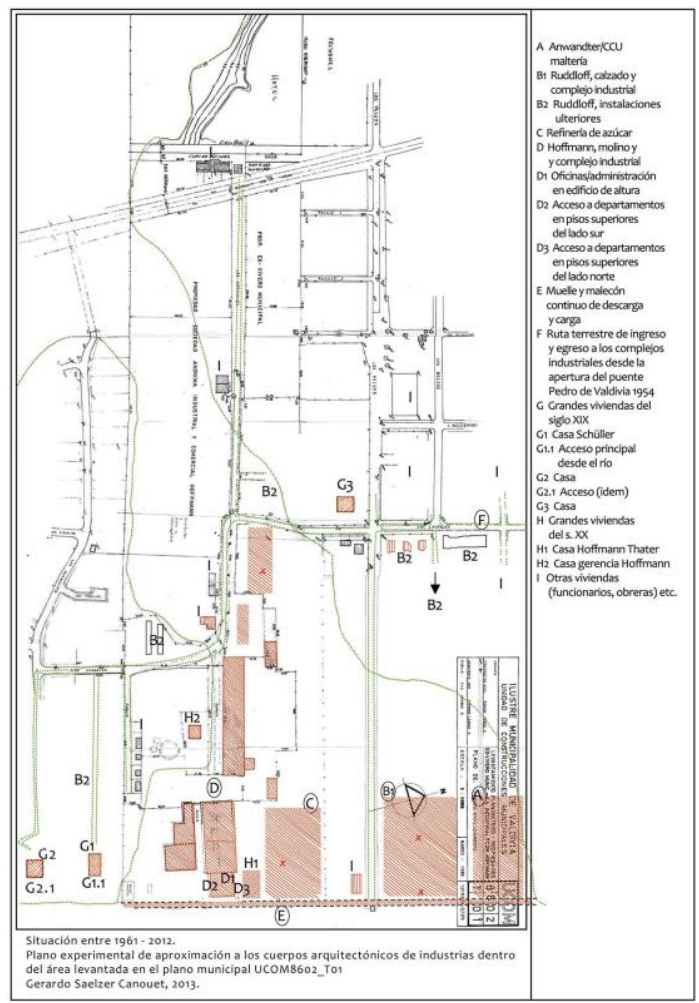

Plano 6 Complejo Industrial Hoffmann, Isla Teja, ca. 1873-1960.

Fuente: Elaboración propia en base a plano municipal UCOM 8602 T01, 1986. 


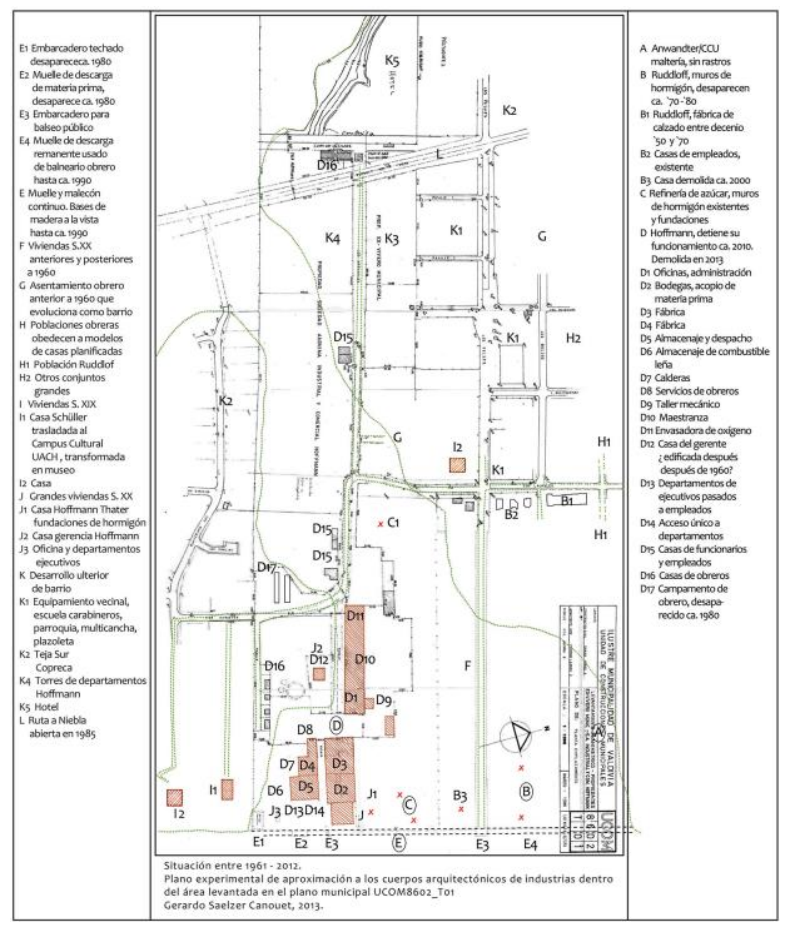

Plano 7 Complejo Industrial Hoffmann, Isla Teja, ca. 1961-2012.

Fuente: Elaboración propia en base a plano municipal UCOM 8602 T01, 1986.

Las vistas panorámicas, las cartas de inmigrantes ${ }^{18}$ y los relatos de viajeros -buena parte como expediciones científicas-, forman una carga de complejas observaciones que se integran al imaginario colectivo (Shama, 1995: 10) de los habitantes de Valdivia. Como umbrales y pasajes en el espacio recordado e imaginado, sobrevivirán culturalmente al tiempo (Assmann, 1999: 281-282; véase también Mongin, 2006: 57-59), permitiendo que el urbanismo fluvial se integre como una idea y visión al imaginario de la ciudad.

A nivel de paisaje urbano surgen conflictos territoriales de connotación cultural, configurados en la alteración de las interfaces entre historia de la ciudad y peso territorial. Las fuentes históricas de un patrimonio que desaparece materialmente pero sobrevive en imágenes colectivas, tanto memoria como fotografías, son los asentamientos industriales, la irrupción de viviendas burguesas y de barrios obreros y la movilidad sobre el río. Como por ejemplo: los terrenos del complejo industrial Hoffmann y su abandono (ver Fig. 1b); la edificación de la Contraloría General de la República; el confinamiento de la estación de ferrocarriles para la extensión de la Costanera y la relegación del tren en restauración a un patio que inhabilita movimientos y protección; la demolición reciente de los muros de los almacenes ferroviarios-fluviales (ver Fig. 1a); la Costanera Cultural-peatonal y el edificio nuevo para el Museo de Arte Contemporáneo en los terrenos y ruinas de la cervecería CCU, anteriormente Anwandter Hnos; el proyecto del puente Los Pelúes con bajada hacia el área del torreón de Los Canelos y la Zona Típica en el Área

\footnotetext{
18 Pueden ser considerados en este elenco, Gay, Fitz Roy, Darwin, Philippi, Döll, Treutler, Blancpain, Simonds, Anwandter; Kirchhof, Hetd, Kunz, Ivens, entre otros; mientras Valk, al igual que Knittel, que perpetúan su observación del espacio urbano y fluvial a través de las fotografías, muchas editadas como postales (Alvarado y Matthews, 2005 y 2006).
} 
Fundacional además del área industrial de la Isla Teja en el perdió entre Rudloff y Hoffmann (ver Fig. 2a).

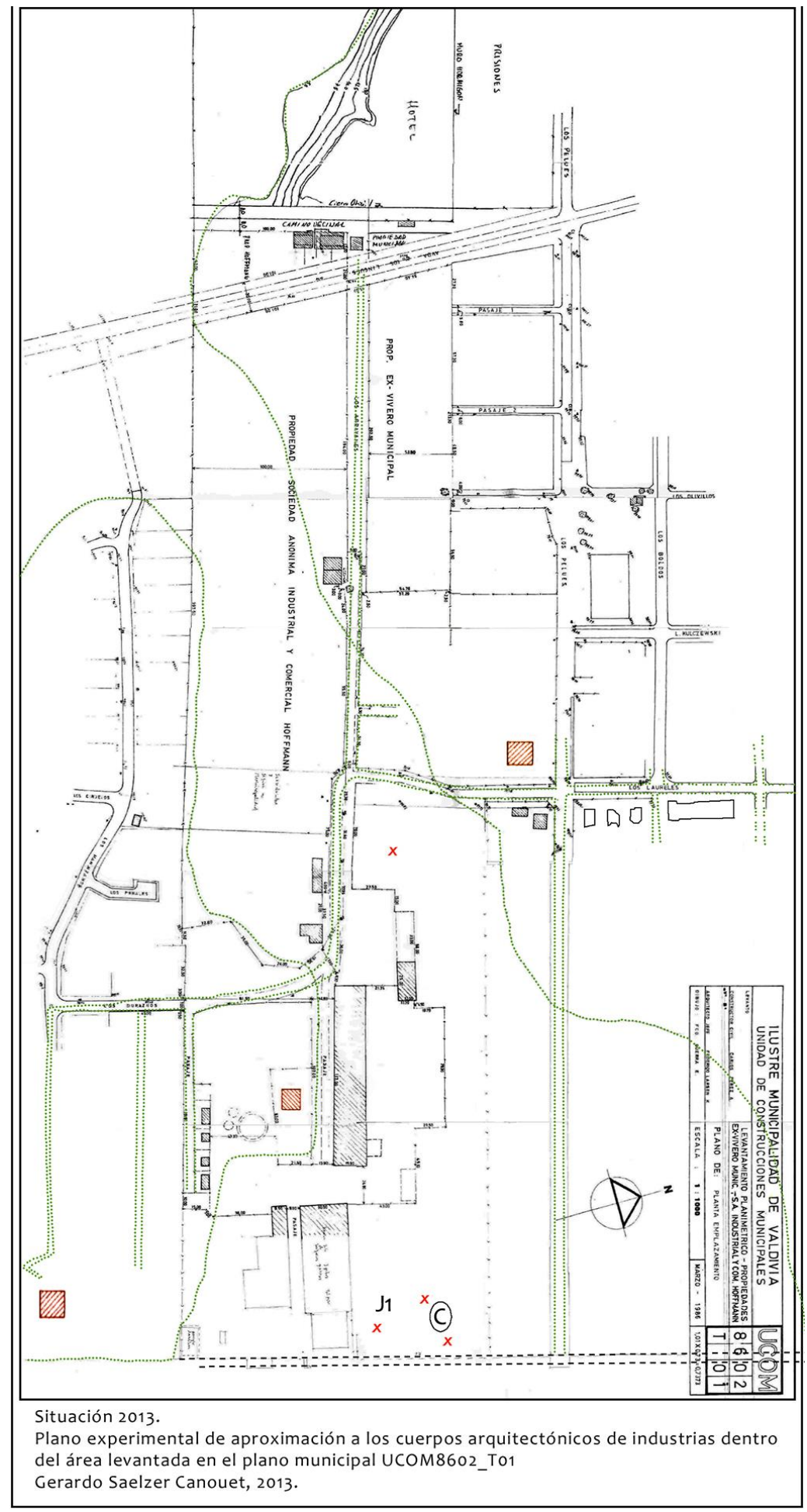

Plano 8 complejo Industrial Hoffmann, Isla Teja, ca. 2013.

Fuente: Elaboración propia en base a plano municipal UCOM 8602 T01, 1986. 


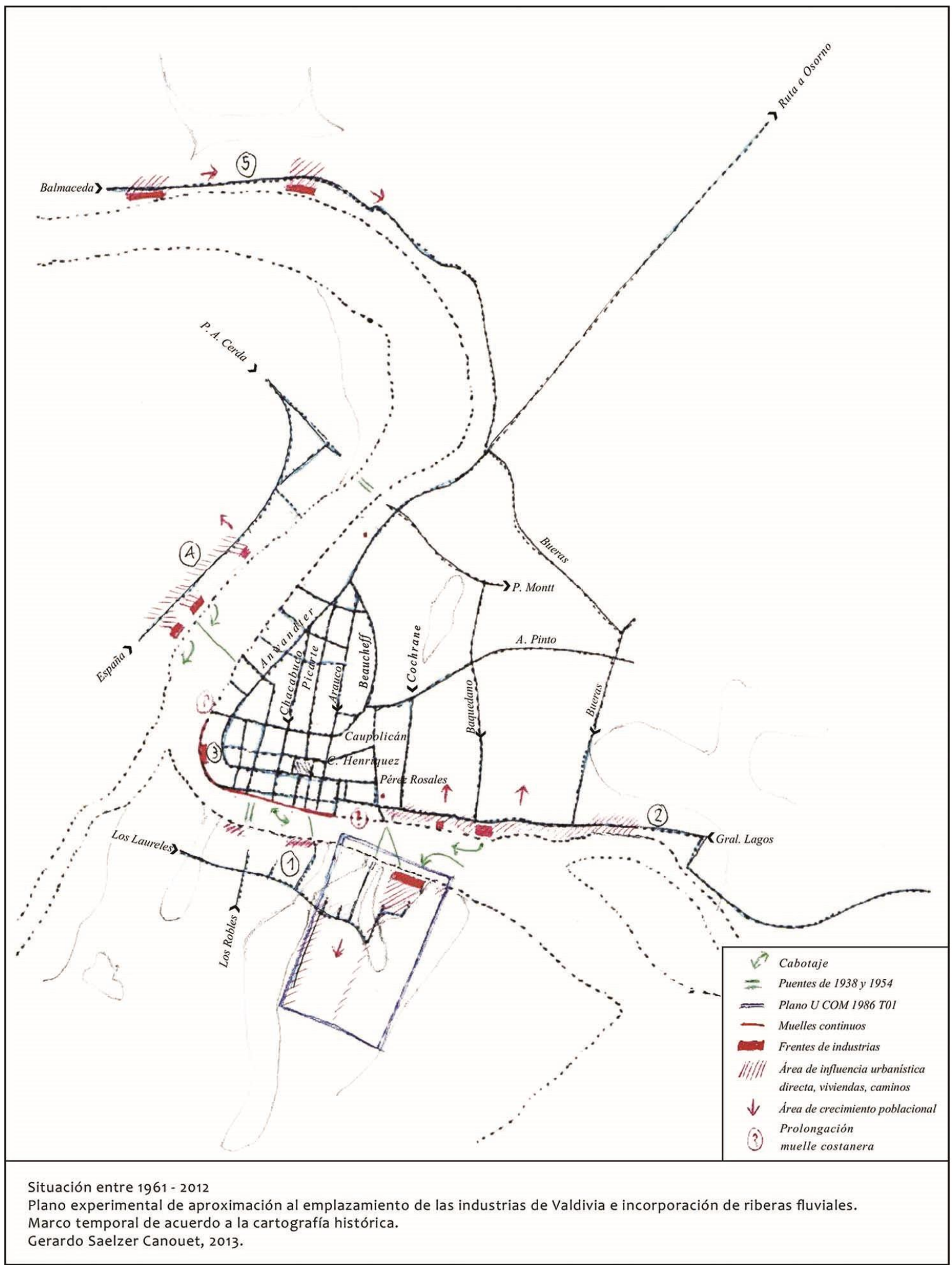

Plano 9 Esquema territorio urbano de Valdivia, ca. 1961-2012.

Fuente: Elaboración propia 


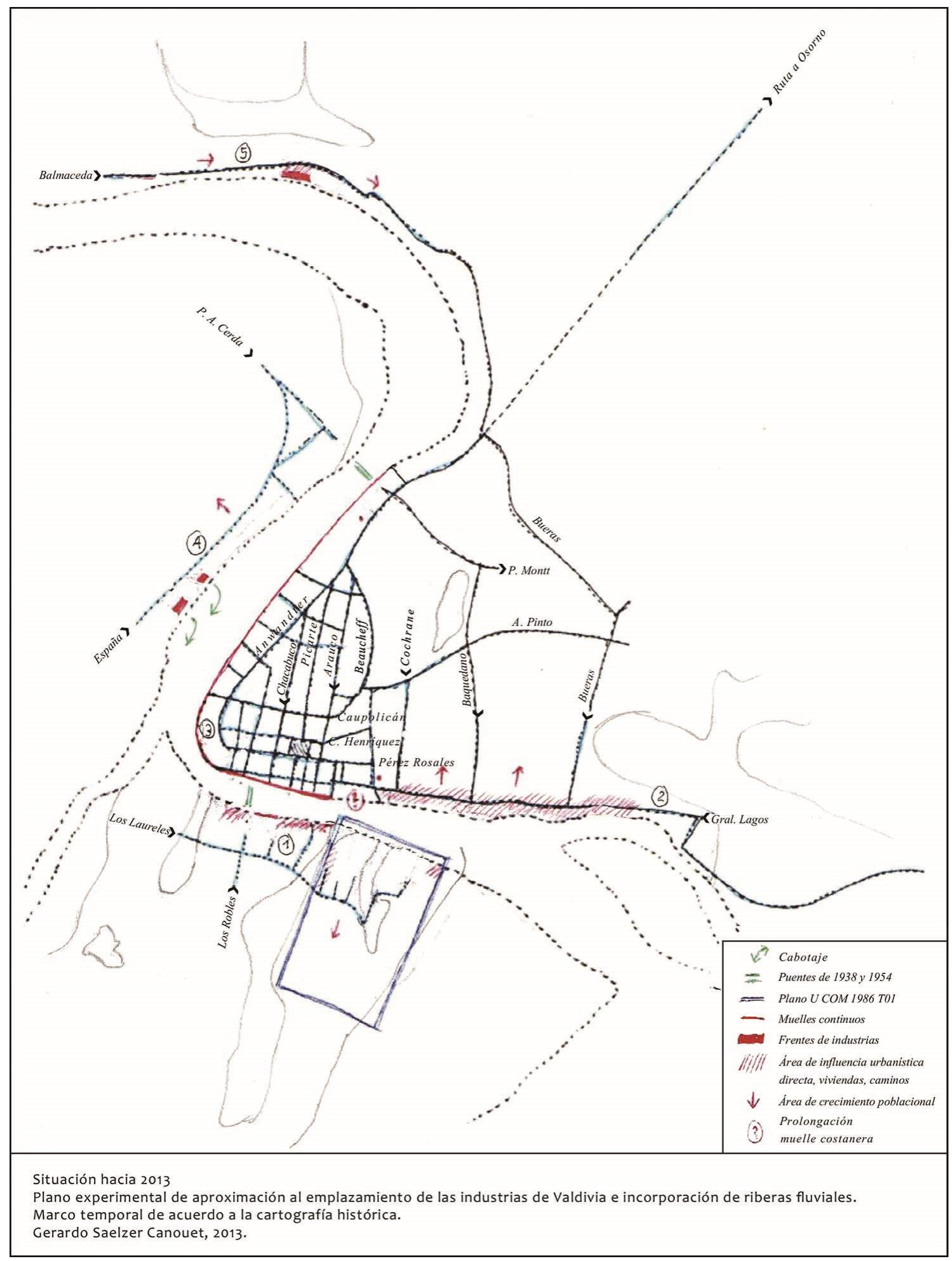

Plano 10 Esquema territorio urbano de Valdivia, ca. 2013. Fuente: Elaboración Propia 
A nivel de paisaje urbano surgen conflictos territoriales de connotación cultural, configurados en la alteración de las interfaces entre historia de la ciudad y peso territorial. Las fuentes históricas de un patrimonio que desaparece materialmente pero sobrevive en imágenes colectivas, tanto memoria como fotografías, son los asentamientos industriales, la irrupción de viviendas burguesas y de barrios obreros y la movilidad sobre el río. Como por ejemplo: los terrenos del complejo industrial Hoffmann y su abandono (ver Fig. 1b); la edificación de la Contraloría General de la República; el confinamiento de la estación de ferrocarriles para la extensión de la Costanera y la relegación del tren en restauración a un patio que inhabilita movimientos y protección; la demolición reciente de los muros de los almacenes ferroviarios-fluviales (ver Fig. 1a); la Costanera Cultural-peatonal y el edificio nuevo para el Museo de Arte Contemporáneo en los terrenos y ruinas de la cervecería CCU, anteriormente Anwandter Hnos; el proyecto del puente Los Pelúes con bajada hacia el área del torreón de Los Canelos y la Zona Típica en el Área Fundacional además del área industrial de la Isla Teja en el perdió entre Rudloff y Hoffmann (ver Fig. 2a).

Este conjunto ofreció una cierta especialización del espacio fluvial y de sus riberas. De esta especialización se hacen cargo políticas como los paisajes culturales ${ }^{19}$, afianzándose en ellos la idea del carácter del territorio a partir de los conceptos estéticos de Cullen (1981), el imaginario artístico (Maderuelo, 2010) y la integración de conocimientos ecológicos (Collinge, 2009).

Desde la primera etapa de urbanismo fluvial en Valdivia, el paisajismo lo constituye el peso urbano acumulado sobre el espacio fluvial. El primer conflicto se radica en el surgimiento de capas inmobiliarias y urbanizaciones viales sobre el antiguo mosaico de extensión urbana en las riberas, bajo la última fase de vida, no utilitaria, que se debate entre el eriazo y la formación del recuerdo. El acercamiento al conflicto identifica como posible solución la planificación del paisaje y la integración de la ecología regional en el paisaje urbano (Forman, 1995: 449 y 459 ; Collin, 2009: 254-255), elementos previstos en los paisajes culturales, cuyo lenguaje en el caso del urbanismo fluvial lo forman los modelos y las potenciales metáforas de un espacio (antes) estructurado.

\section{Discusión y conclusiones}

La incorporación del río a la ciudad, que transforma el paradigma colonial del urbanismo en Valdivia en uno de adaptación fisiográfica, se debe a la evidencia que entregan documentos visuales, referentes bibliográficos y referentes de las ciudades-puerto-fluvial. Así también, la idea de la ciudad arraigada al río como origen de preocupaciones urbanísticas se encuentra en la actividad académica del Instituto de Arquitectura de la Universidad Austral de Chile (Arentsen et al., 2013).

\subsection{Estéticas, éticas y políticas: la desaparición de las formas arquitectónicas.}

Considerando el análisis presentado, los procesos urbanos que consignamos como urbanismo fluvial, consolidado entre $1873 / 1876$ y 1960 , son recursos arquitectónicos, urbanos y conceptualizaciones del territorio. A través de la documentación presentada son posibles de estudiar en formato visual (documentación histórica) y físico (in situ) que, originados en un proceso histórico, situaron al río como un factor de desarrollo. Rescatado como evidencia cultural, sus elementos se transforman en materia para políticas territoriales y planificaciones estratégicas. Los componentes en Valdivia surgen desde estrategias de comunicación y

${ }^{19}$ Como aborda la Estrategia Territorial Europea (1999) y Convenio Europeo del Paisaje (2004). 
desplazamientos de los puntos de vista, que transforman el río en eje y en paisaje urbano (Felsenhardt, 2006: 2-3) 20 $^{2}$ La desaparición del urbanismo fluvial genera la reaparición del borde preurbano junto con la acción urbanizadora inmobiliaria. Los síntomas del conflicto se encuentran en la demanda de suelos, en función del rendimiento económico, que excluyen la etapa histórica del urbanismo fluvial. Es por ello que asoman en este trabajo las discusiones de Assmann sobre la metamorfosis de recordar: el arte de la memoria y -según la materialidad del medio- las metáforas del espacio estructurado (Assmann, 1999: 123, 146, 298, 399-400). Como hábitat, caracterizado por un modelo comunitario sensible a la restauración (Collinge, 2009: 222-223), permite comprender el proceso de este macroespacio de Valdivia analizado a la luz del apogeo industrial, establecido territorialmente a lo largo del cauce. La adopción del río por la ciudad, como hábitat es fuente de desarrollo cultural pro sustentabilidad, propuestas a partir del concepto de paisajismo urbano de Field Operations (Corner, 2005).

La intensa ocupación del espacio fluvial, asentada en la memoria y operada como cualidad panorámica según las evidencias fotográficas y arqueológicas, permite entender el espacio fluvial como Área Fundacional de la actual ciudad. Se consideran los bordes como conectores entre sucesión ecológica (Shugart, 1984), bien público y recursos históricos, que ingresan como actores para posicionarse dentro de la planificación territorial local. Así también en las intervenciones sectoriales y en los procesos inmobiliarios actualmente de pequeña y mediana escala. Contamos primeramente con un cultivo del saber por imágenes, modos de vida conservados en la retina "que en el presente se intuyen como excepciones" y que rescatamos como significativamente se hace con las fotografías de una "historia que se visualiza en extinción" (Traverso, 2011: 59). Así es como, ulteriormente por herencia, se esclarece el recuerdo como cultura para los proyectos de construcción de identidad (Assmann, 199: 85 y 92). Se trata aquí del marco espacial de la vida diaria de la gente y del actuar en respuesta a la amenaza sobre paisajes culturales, tal que permita modularse el paisaje urbano por discernimiento, manejar los efectos del deterioro y escapar de las causalidades.

Sobre el peso territorial acumulado por Valdivia, se halla el contrapeso de las fuerzas urbanizadoras actuales. Se acusa una hegemonía capaz de abatir las dinámicas históricas, como el paisaje industrial en ruinas o el surgimiento de metáforas; y un bien, como la generación espontánea de una primera urbanización. Conflictos entre ambas fuerzas se advierten en la alteración de interfaces entre edificación de ciudad y paisaje; espacio y memoria; identidad y cultura $^{21}$. Aunque no necesariamente, se converge a un sitio protegido, la arqueología urbana se funda en el simple compromiso con el conocimiento del territorio de los espacios excepcionales, portadores de patrimonio; es decir, el cruce con el desarrollo social (Yázigi, 2009: 339). Una reconquista de principios de patrimonio ambiental urbano, se erige como respuesta para resolver los abandonos a través de planificaciones de la calidad, de los territorios, como así la convergencia de los varios dominios del saber (Yázigi, 2009: 56 y 148-150). La recuperación de los espacios excepcionales abordaría la última fase de vida material no utilitaria de un objeto que da lugar a despojos y a la excavación que conecta con el espacio y el tiempo: la memoria y sus fuentes. Es decir, desde la funcionalidad del río a la sensibilidad estética, de regreso a la funcionalidad social de la ciudad.

Las investigaciones arqueológicas recientes han comenzado a determinar lugares específicos del apogeo industrial de Valdivia y operación urbana (Urbina et al., 2012: 5 y 7). Ejemplo de ello es

20 Territorio, como suelo, es divisible, fragmentable, repartible. Paisaje es continuo y es un bien de todos sin ser dueños.

21 Zonas de protección por valor ambiental, reconocidas por la institucionalidad a través de legislación y las normas para resguardarlas. En estos términos, el paisaje es un bien y es un recurso valioso de desarrollo (Felsenhardt, 2006: 3). 
el estudio del sitio Contraloría Regional, con una superficie excavada cercana a $110 \mathrm{~m}^{2}$ correspondiente a fundaciones y subterráneo de la Aduana (Mera et al., 2014: 301). Se suman a aquellos testigos, intervenciones estratigráficas en contextos residenciales como el sitio residencial Casa Prochelle 1 (Isla Teja) y Casa Luis Oyarzún-UACh (calle Yungay), y el registro superficial de distintos puertos fluviales e infraestructura asociada en estado de abandono ruinas- en el derrotero del río Cruces, comuna de Mariquina (p.e. puerto Paico y Cuyinhue).

Cabe preguntarse cuál es la evidencia física de la infraestructura industrial que estuvo a la vista en la ciudad de Valdivia durante los siglos XIX y XX, y qué características tuvo como para afirmar que el urbanismo que aparece con la primera ocupación de riberas enfrentadas es un aporte para la reflexión y el fomento de planes de desarrollo estratégicos, como la incorporación del paisajismo a los programas formativos y de gestión del territorio.

Agradecimientos: Este artículo es resultado del proyecto Fondecyt 1130730. A la Dirección Museológica de la Universidad Austral de Chile, especialmente a Leonor Adán. A Boris Borneck por permitirnos la consulta y reproducción de fotografías pertenecientes a sus archivos. A Felipe Arias y Paulina Chávez por el apoyo a elaboración y edición final de los planos. Al Instituto de Arquitectura y Urbanismo y de Historia y Ciencias Sociales de la Universidad Austral de Chile.

\section{Bibliografía}

Almonacid, Fabián. La industria valdiviana en su apogeo (1870-1914). Ediciones Universidad Austral de Chile, Kultrún. Valdivia, 2013.

Alvarado, Margarita y Mariana Matthews. Los pioneros Valck. Un siglo de fotografía en Chile. Volumen I, Colección Relatos del Ojo y la Cámara. Pehuén Editores. Santiago, 2005.

Alvarado, Margarita y Mariana Matthews. Rodolfo Knittel. Fotógrafo y viajero en el sur de Chile. Volumen II, Colección Relatos del Ojo y la Cámara. Pehuén Editores. Santiago, 2006.

Álvarez, Luis y Víctor Navarro. Análisis geo-Histórico de espacio urbano del barrio del Almendral Valparaíso, entre la Av. Argentina y la Av. Francia, hacia 1835-1842. Revista Geográfica de Valparaíso n²2-23, 1994.

Aranda, Diego, Llarena, José y Rafael Tenajo. La Colonia Alemana en Chile. Ediciones Aranda, Llarena y Tenajo, Santiago, 1920.

Arentsen, Eric, Valderrama, Cristian y Sepúlveda, Carolina. Parque lineal borde fluvial Valdivia. Revista AUS nº13, 2013, pp.30-33.

Assmann, Aleida. Erinnerungsräume: Formen und Wandlung des Kulturellen Gedächtniss. C. H. Beck, München, 1999.

Bernedo, Patricio. Los industriales alemanes de Valdivia, 1850-1914. Revista Historia Vol. 32, 1999, pp. $5-42$.

Bianchi, Álvaro. Compraventa Ilustre Municipalidad de Valdivia a Augusto Herrmann y otros. Revista de Derecho, Vol. VIII, 1997, pp. 199-201.

Blohmayer, Dirk. Alte Hülle, Neue Vision, Speicherstadt Potsdam. Cw-Verlagsgruppe, 2002.

Borneck, Boris y José Manuel Izquierdo. El gran incendio: Valdivia 1909. Arte Sonoro Austral Ediciones, Valdivia, 2009.

Collinge, Sharon. Ecology of fragmented landscapes. John Hopkins University Press. Baltimore, Ma., Estados Unidos, 2009. 
Comité de Desarrollo Territorial. Estrategia Territorial Europea: hacia un desarrollo equilibrado y sostenible del territorio de la UE. Comisión Europea, 1999.

Consejo de Europa. Convenio Europeo del Paisaje. Secretaría General, 2004.

Corner, James. 2005 "Terra Fluxus", en Waldheim, Ch. (ed.), The Landscape Urbanism Reader. Nueva York: Princeton Architectural Press, pp. 13-33.

Corner, James. "Lifescape-Fresh Kill Parkland". Revista Topos: International Review of Landscape Architecture and Urban Design n 51, 2005, pp. 14-21.

Cullen, Thomas. El paisaje urbano. Tratado de estética urbanística. Barcelona, Ed. Blume, 1981.

Felsenhardt, Cristina. Ciudad y Paisaje. Permutas contemporáneas del territorio. Revista 180, n¹7, 2006, pp. 2-3.

Forman, Richard. Land Mosaics: the ecology of landscape and regions. Cambridge University Press. Cambridge, Reino Unido, 1995.

Gómez, Domingo. Ordenación Territorial. Mundi-Prensa y Editorial Agrícola Española, Madrid, 2008.

Guarda, Gabriel. La economía de Chile Austral antes de la colonización alemana 1645-1850. Universidad Austral de Chile, Valdivia, 1973.

Guarda, Gabriel. Nueva Historia de Valdivia. Ediciones Pontificia Universidad Católica de Chile, Santiago, 2001.

Guarda, Gabriel. Cuatro siglos de evolución urbana, Valdivia 1552-1910. Universidad Austral de Chile, Instituto de Arquitectura y Urbanismo, Valdivia, 2009.

Grossbach, Günther. Carlos Anwandter, Biographie. Instituto Alemán Carlos Anwandter, Valdivia, 2005.

Lorenzo, Santiago. Origen de las Ciudades Chilenas, las Fundaciones del Siglo XVIII. Editorial Andrés Bello, Santiago, 1986.

Maderuelo, Javier. Paisaje y Patrimonio. Madrid: Abada editores, 2010.

Martin, Matl. Kulturspeicher in Würzburg. Bauwelt n¹4, 2002, pp. 12-17.

Mera, Rodrigo, Simón Urbina y Doina Munita. Rescate arqueológico en la obra construcción edificio sede Contraloría Regional Valdivia, Región de Los Ríos. Informe Final. Consejo de Monumentos Nacionales, 2014.

Mongin, Oliver. La condición urbana: la ciudad a la hora de la mundialización. Paidós, Buenos Aires, 2006.

Muñoz, Susana. Casa Anwandter: Recorrido histórico y análisis para su recuperación estética. Revista Austral de Ciencias Sociales n9, 2005, pp. 25-37.

Pellegrini y Aprile. El progreso Alemán en América. Tomo I, Chile. Editorial Río de la Plata. Santiago, Chile, 1924.

Philippi, Rodulfo. Los orígenes de la Colonización Alemana en Chile. En Los Alemanes en Chile su primer centenario. Santiago, Liga chileno alemana, 1950.

Pinto, Julio y Verónica Valdivia. ¿Chilenos Todos? La Construcción Social de la Nación 1810-1840. Editorial LOM, Santiago, 2009.

Saelzer, Gerardo. 2014. Urbanismo topográfico según la cartografía histórica, desde las fortificaciones hasta las plazas de Valparaíso. AUS no15, 2014, pp. 34-39.

Selingardi-Sampaio, Silvia. Industria e Territorio em Sao Paulo, 1950-2005. Alinea Editora, Sao Paulo, 2009. 
Shama, Simón. Introducción. En Landscape and Memory. New York Ventage Boohs Ed. Nueva York, 1995, pp. 3-19.

Shugart, Herman. A theory of forest dynamics: the ecological implications of forest succession models. Sringer-Verlag, New York, Estados Unidos, 1984.

Traverso, Ana. El espejo de la memoria. En Amor x Chile (Julia Toro Eds.). Ocholibros, Santiago, 2011, pp. 58-63.

Treutler, Paul. Andanzas de un Alemán en Chile. 1851-1863. Traducción Carlos Keller, Editorial del Pacifico, Santiago, 1958.

Urbina, Simón Leonor Adán, Doina Munita y Rodrigo Mera. 2012. Arquitectura arqueológica y sitios patrimoniales sin arquitectura en el perímetro urbano de Valdivia: cartografía descriptiva actualizada y comentarios sobre su valor científico integral. Revista AUS n²12, 2012, pp. 4-9.

Wilson, Ariane. Alte und Neue Identitäten, zur Typologie der Hafenstädte und der Gefahr ihrer Selbstauflösung. Werk, Bauen+Wohnen n05, 2002, pp. 11-15.

Yazigi, Eduardo (Editor). Turismo e Paisagem. Contexto, Sao Paulo, 2002.

Yazigi, Eduardo. Saudades do Futuro: Por uma Teoria do Planejamento Territorial do Turismo. Plêiade, Sao Paulo, 2009. 